\title{
ESE Clinical Practice Guideline on functioning and nonfunctioning pituitary adenomas in pregnancy
}

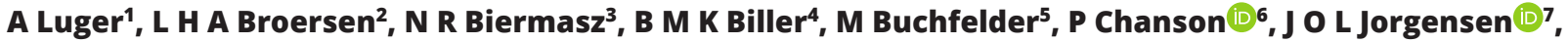 \\ F Kelestimur ${ }^{8}$, S Llahana ${ }^{9}$, D Maiter ${ }^{10}$, G Mintziori ${ }^{11}$, F Petraglia ${ }^{12}$, R Verkauskiene ${ }^{13}$, S M Webb ${ }^{14}$ and \\ O M Dekkers 1 15, 16,17
}

${ }^{1}$ Clinical Division of Endocrinology and Metabolism, Department of Medicine III, Medical University of Vienna, Vienna, Austria, ${ }^{2}$ Division of Endocrinology, Department of Medicine, Leiden University Medical Center, Leiden, The Netherlands, ${ }^{3}$ Division of Endocrinology, Department of Medicine, Pituitary Center and Center for Endocrine Tumors, Leiden University Medical Center, Leiden, The Netherlands, ${ }^{4}$ Neuroendocrine \& Pituitary Tumor Clinical Center, Massachusetts General Hospital, Harvard Medical School, Boston, Massachusetts, USA, ${ }^{5}$ Department of Neurosurgery, University Hospital Erlangen, Erlangen, Germany, ${ }^{6}$ Université Paris-Saclay, Inserm, Physiologie et Physiopathologie Endocriniennes, Assistance Publique-Hôpitaux de Paris, Hôpital Bicêtre, Service d'Endocrinologie et des Maladies de la Reproduction et Centre de Réference des Maladies Rares de l'Hypophyse, Le Kremlin-Bicêtre, France, ${ }^{7}$ Department of Endocrinology and Internal Medicine, Aarhus University Hospital, Aarhus, Denmark, ${ }^{8}$ Department of Endocrinology, Yeditepe University, Istanbul, Turkey, ${ }^{9}$ School of Health Sciences, City, University of London, London, UK, ${ }^{10}$ Department of Endocrinology and Nutrition, Cliniques Universitaires Saint-Luc, Université Catholique de Louvain, Brussels, Belgium, ${ }^{11}$ Unit of Reproductive Endocrinology, First Department of Obstetrics and Gynecology, Aristotle University of Thessaloniki Medical School, Thessaloniki, Greece, ${ }^{12}$ Department of Obstetrics and Gynecology, University of Florence, Florence, Italy, ${ }^{13}$ Institute of Endocrinology, Medical Academy, Lithuanian University of Health Sciences, Kaunas, Lithuania, ${ }^{14}$ IIB-Sant Pau and Department of Endocrinology/Medicine, Hospital Sant Pau, Universitat Autónoma de Barcelona, and Centro de Investigación Biomédica en Red de Enfermedades Raras (CIBER-ER, Unit 747), ISCIII, Barcelona, Spain, ${ }^{15}$ Department of Clinical Epidemiology, Leiden University Medical Center, Leiden, The Netherlands, ${ }^{16}$ Department of Clinical Endocrinology, Leiden University Medical Center, Leiden, The Netherlands, and ${ }^{17}$ Department of Clinical Epidemiology, Aarhus University, Aarhus, Denmark

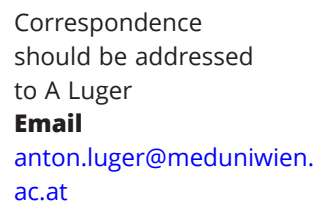

\begin{abstract}
Pregnancies are rare in women with pituitary adenomas, which may relate to hormone excess from secretory subtypes such as prolactinomas or corticotroph adenomas. Decreased fertility may also result from pituitary hormone deficiencies due to compression of the gland by large tumours and/or surgical or radiation treatment of the lesion. Counselling premenopausal women with pituitary adenomas about their chance of conceiving spontaneously or with assisted reproductive technology, and the optimal pre-conception treatment, should start at the time of initial diagnosis. The normal physiological changes during pregnancy need to be considered when interpreting endocrine tests in women with pituitary adenomas. Dose adjustments in hormone substitution therapies may be needed across the trimesters. When medical therapy is used for pituitary hormone excess, consideration should be given to the known efficacy and safety data specific to pregnant women for each therapeutic option. In healthy women, pituitary gland size increases during pregnancy. Since some pituitary adenomas also enlarge during pregnancy, there is a risk of visual impairment, especially in women with macroadenomas or tumours near the optic chiasm. Pituitary apoplexy represents a rare acute complication of adenomas requiring surveillance, with surgical intervention needed in some cases. This guideline describes the choice and timing of diagnostic tests and treatments from the pre-conception stage until after delivery, taking into account adenoma size, location and endocrine activity. In most cases, pregnant women with pituitary adenomas should be managed by a multidisciplinary team in a centre specialised in the treatment of such tumours.
\end{abstract}




\section{Overview of recommendations}

\section{General recommendations: Pre-conception stage}

R.1.1. We recommend that women of reproductive age with a diagnosis of a pituitary adenoma be counselled about their potential fertility and pregnancy outcomes as early as possible.

R.1.2. We recommend that women of reproductive age with a diagnosis of pituitary adenoma, functioning or nonfunctioning, who consider pregnancy, be managed by an endocrinologist.

R.1.3. We recommend that management of women of reproductive age with a large pituitary adenoma $(>1 \mathrm{~cm})$, Cushing's disease or acromegaly, who consider pregnancy, be discussed in a multidisciplinary team.

R.1.4. We recommend that in women with a diagnosis of pituitary adenoma and hypopituitarism, hormone replacement therapy should be initiated or optimised prior to becoming pregnant.

\section{General recommendations: Pregnancy}

R.2.1. We recommend that pregnant women with a known pituitary adenoma, in particular those with a large pituitary adenoma $(>1 \mathrm{~cm})$, Cushing's disease or acromegaly, and those with pituitary deficiencies, should be followed by an endocrinologist and an advanced nurse practitioner where relevant. The frequency depends on the underlying condition and individualised needs.

R.2.2. We recommend that pregnant women with diagnosed hypopituitarism should have regular clinical and hormonal follow-up by an endocrinologist and an advanced nurse practitioner where relevant.

R.2.3. We recommend that women and their partners be provided with education for glucocorticoid stress dose adjustment and measures on how to prevent or manage adrenal crisis during pregnancy.

R.2.4. We recommend performing an MRI without contrast in pregnancy in case of symptoms of tumour progression or apoplexy.

R.2.5. We recommend that neuro-ophthalmologic examination in pregnancy be performed for adenomas impinging visual pathways or in case of suspected tumour progression or pituitary apoplexy.

R.2.6. We recommend considering surgery in pregnant women with deterioration of vision, ophthalmoplegia or severe headache attributable to tumour enlargement if medical tumour treatment is unfeasible or ineffective $(\oplus \oplus \circ \bigcirc)$.

R.2.7. If surgery is indicated, we suggest to perform transsphenoidal surgery in the second trimester if the clinical course allows this $(\oplus \oplus \bigcirc)$ ).

R.2.8. We recommend not to perform radiotherapy during pregnancy.

\section{General recommendations: Delivery and breastfeeding}

R.3.1. We suggest that pregnant women with pituitary adenomas should receive standard obstetrical care but recommend close maternal and foetal surveillance.

R.3.2. In general, breastfeeding is feasible and not contraindicated.

\section{Nonfunctioning adenomas (NFAs)}

R.4.1. In women with an NFA near the optic chiasm who are planning a pregnancy, surgery may be considered to reduce the risk of chiasmal compression and to enhance fertility.

R.4.2. We suggest that for women with intrasellar nonfunctioning microadenomas and an uneventful pregnancy, there is no need for routine endocrinological follow-up during pregnancy.

R.4.3. We recommend that for macroadenomas and/or extrasellar NFAs, neuro-ophthalmologic and, if indicated, MRI examination should be performed only in case of symptoms of tumour progression or pituitary apoplexy during pregnancy.

R.4.4. We recommend that in case of a clinical need to reduce adenoma volume during pregnancy, surgery is the preferred option $(\oplus \circ \bigcirc)$ ).

R.4.5. We recommend awaiting reassessment of pituitary imaging and function until after delivery and breastfeeding.

\section{Prolactinomas}

R.5.1. We recommend treating women with a prolactinoma, who are actively seeking pregnancy, with a dopamine agonist and strive for normalisation of prolactin concentrations and restoration of regular ovulatory cycles $(\oplus \oplus \oplus \bigcirc)$.

R.5.2. We recommend medical treatment as first-choice therapy for women with a prolactinoma and actively 
seeking pregnancy; transsphenoidal surgery can be considered in individual cases $(\oplus \oplus \oplus \bigcirc)$.

R.5.3. We recommend cabergoline as medical treatment at the lowest possible effective dose until pregnancy is confirmed $(\oplus \oplus \bigcirc \bigcirc)$.

R.5.4. We recommend stopping the dopamine agonist once pregnancy is established. However, dopamine agonists may be given for a longer gestational period in specific circumstances $(\oplus \bigcirc \bigcirc \bigcirc)$.

R.5.5. We recommend not measuring prolactin during pregnancy.

R.5.6. We suggest that for women with a small intrasellar microprolactinoma, and normal pituitary function prepregnancy, there is no need for routine endocrinological follow-up during pregnancy.

R.5.7. We suggest careful and regular monitoring for tumour growth in pregnant women with a large macroprolactinoma or a prolactinoma close to the optic chiasm $(\oplus \oplus \bigcirc \bigcirc)$.

R.5.8. We recommend to consider restarting dopamine agonists in pregnancy in case of symptoms of progressive prolactinoma growth. Surgery should be used only in case of medical failure or symptomatic apoplexy $(\oplus \bigcirc \bigcirc)$ ).

R.5.9. For women with a prolactinoma, breastfeeding is usually feasible and not contraindicated, but we recommend to take into account individual circumstances like tumour size and symptoms.

R.5.10. We recommend reassessing prolactinoma status after every pregnancy before considering restarting therapy.

\section{Acromegaly}

R.6.1. In women with acromegaly considering pregnancy, we recommend assessment of disease activity, comorbidities and fertility status.

R.6.2. In women with newly diagnosed acromegaly seeking pregnancy, surgery is recommended as first-line therapy.

R.6.3. In women with mild acromegaly, no comorbid conditions and regular ovulatory cycles, pregnancy is considered safe and medical or surgical treatment can be postponed until after delivery.

R.6.4. We suggest that for women with acromegaly seeking pregnancy and who have an indication for medical treatment, somatostatin analogues or cabergoline can be used until confirmation of pregnancy if surgery is not an option. Pegvisomant should be reserved for selected uncontrolled cases $(\oplus \bigcirc \bigcirc \bigcirc)$.

R.6.5. We recommend to consider stopping drugs for acromegaly once pregnancy is established $(\oplus \bigcirc \bigcirc \bigcirc)$.

R.6.6. We recommend not to measure GH and IGF-I during pregnancy.

R.6.7. We suggest that for pregnant women with large adenomas, or adenomas close to the optic chiasm, regular neuro-ophthalmologic and, if necessary, pituitary MRI examination be performed.

R.6.8. We suggest to consider starting or restarting medical treatment for tumour control and severe clinical symptoms attributable to acromegaly $(\oplus \bigcirc \bigcirc \bigcirc)$.

R.6.9. In acromegaly, breastfeeding is feasible and not contraindicated, but we recommend to take individual circumstances like drug use and disease activity into account.

R.6.10. We recommend reassessing disease activity after pregnancy.

\section{Cushing's disease}

R.7.1. We recommend that women with active Cushing's syndrome be advised not to get pregnant.

R.7.2. Evaluation of hypercortisolism during pregnancy is difficult; we suggest to consider testing only for high clinical suspicion of a new diagnosis of Cushing's disease.

R.7.3. We recommend that in women with Cushing's disease, medically treated and considering pregnancy, pros and cons of different therapeutic options to reduce cortisol should be carefully considered ( $\oplus \bigcirc \bigcirc \bigcirc)$.

R.7.4. We recommend that pregnant women with active or medically treated Cushing's disease should be managed by a multidisciplinary team expert in high-risk pregnancies.

R.7.5. We suggest to consider treating pregnant women with active Cushing's disease with prophylactic anticoagulation (low molecular weight heparin (LMWH)).

R.7.6. We recommend to reassess disease activity after pregnancy.

R.7.7. We recommend that breastfeeding be considered.

Our core recommendations are presented in Table 1. 
Table 1 Core recommendations.

\begin{tabular}{|c|c|c|c|c|}
\hline & NFA & Prolactinoma & Acromegaly & Cushing's disease \\
\hline Pre-conception & $\begin{array}{l}\text { In women with an NFA near } \\
\text { the optic chiasm who are } \\
\text { seeking pregnancy, } \\
\text { surgery may be } \\
\text { considered to reduce the } \\
\text { risk of chiasmal } \\
\text { compression and to } \\
\text { enhance fertility }\end{array}$ & $\begin{array}{l}\text { Aim for normalisation of } \\
\text { even mild } \\
\text { hyperprolactinaemia with } \\
\text { cabergoline at the lowest } \\
\text { possible dose to optimise } \\
\text { chances to conceive }\end{array}$ & $\begin{array}{l}\text { Consider surgery in } \\
\text { active acromegaly } \\
\text { before pregnancy }\end{array}$ & $\begin{array}{l}\text { Advise against pregnancy } \\
\text { during active Cushing's } \\
\text { disease }\end{array}$ \\
\hline Pregnancy & $\begin{array}{l}\text { Nonfunctioning } \\
\text { microadenomas bear a } \\
\text { low risk for growth during } \\
\text { pregnancy, there is no } \\
\text { need for routine } \\
\text { monitoring }\end{array}$ & $\begin{array}{l}\text { No indication for prolactin } \\
\text { testing } \\
\text { Medical treatment should } \\
\text { be stopped in most cases } \\
\text { upon confirmation of } \\
\text { pregnancy } \\
\text { Close surveillance is needed } \\
\text { in women with a } \\
\text { macroprolactinoma }\end{array}$ & $\begin{array}{l}\text { No indication for GH } \\
\text { and/or IGF-1 testing } \\
\text { Medical treatment } \\
\text { should be stopped } \\
\text { in most cases upon } \\
\text { confirmation of } \\
\text { pregnancy }\end{array}$ & $\begin{array}{l}\text { Diagnosis of Cushing's } \\
\text { disease and assessment } \\
\text { of disease activity is } \\
\text { challenging due to } \\
\text { placental CRH production } \\
\text { and activation of the } \\
\text { hypothalamic-pituitary- } \\
\text { adrenal axis, circadian } \\
\text { rhythm, however, is } \\
\text { preserved }\end{array}$ \\
\hline Post-pregnancy & $\begin{array}{l}\text { We recommend awaiting } \\
\text { reassessment of pituitary } \\
\text { imaging and function until } \\
\text { 3-6 months after delivery }\end{array}$ & $\begin{array}{l}\text { A significant percentage of } \\
\text { prolactinomas are } \\
\text { biochemically in } \\
\text { remission after } \\
\text { pregnancy and lactation }\end{array}$ & $\begin{array}{l}\text { Rebound of disease } \\
\text { activity shortly after } \\
\text { delivery is frequent }\end{array}$ & $\begin{array}{l}\text { Reassessment of disease } \\
\text { activity should be } \\
\text { performed 2-3 months } \\
\text { post-partum }\end{array}$ \\
\hline
\end{tabular}

\section{Introduction: The pituitary gland and endocrine milieu in pregnancy}

Pregnancy changes the morphology and function of the pituitary gland. The gland size increases and reaches its maximal volume in late pregnancy and the first days postpartum with a height of up to $12 \mathrm{~mm}$ followed by a gradual decline to normal size within 6 months after delivery $(1,2$, $3)$. This growth is related to lactotroph hyperplasia starting in the first month of pregnancy and due to the increased concentrations of oestradiol $\left(\mathrm{E}_{2}\right)(4)$.

The placenta is a hormone-producing organ that interacts with the pituitary gland. Starting in the first weeks of pregnancy, the placenta produces oestrogens and progesterone, which increase exponentially until delivery, whereas ovarian production subsides $(5,6,7)$. When interpreting hormone concentrations in pregnancy, increased production of binding proteins due to increased oestradiol concentrations has to be considered. In parallel, due to the stimulatory effect of oestradiol, there is an increased prolactin (PRL) production with serum concentrations reaching approximately 6- and 10-fold the upper limit of the reference range of non-pregnant women in the second and third trimester, respectively (7, 8). Human placental lactogen (hPL), which is structurally related to PRL and growth hormone (GH), is released into the maternal circulation from the first weeks of gestation until delivery $(5,6)$.
From gestational week 5, the placenta produces increasing amounts of $\mathrm{GH}(\mathrm{hPGH})$, resulting in suppression of circulating pituitary GH to undetectable levels after gestational week $24(5,8)$. Serum insulin-like growth factor-I (IGF-I) levels increase significantly above the agespecific reference range for non-pregnant women $(5,9)$.

Human chorionic gonadotrophin (hCG) is detectable in the maternal circulation after embryo implantation, peaks around week 10 and thereafter declines until week 20 to lower levels $(10,11)$. hCG is a potent TSH receptor ligand, and therefore, a reciprocal pattern of circulating TSH and hCG is present in the first trimester $(10,12)$. Due to increased concentrations of thyroxine-binding globulin (TBG), circulating levels of total thyroxine (T4) and triiodothyronine $(\mathrm{T} 3)$ are elevated $(10,11)$ in pregnancy, and interpretation of thyroid function tests, therefore, requires appropriate reference ranges $(11,13)$. Free T4 levels decline during pregnancy to levels in the low reference range for non-pregnancy.

Pregnancy is associated with activation of the maternal hypothalamic-pituitary-adrenal (HPA) axis that leads to increased levels of circulating adrenocorticotropic hormone (ACTH) and cortisol (both free and total) as well as $24 \mathrm{~h}$ urinary-free cortisol excretion. The placenta produces large amounts of corticotropin-releasing hormone (CRH) and its related urocortin peptides $(14,15)$, the circulating concentrations of which rise exponentially in the third trimester of pregnancy $(16,17)$. 
The placenta has also 11ß-hydroxysteroid dehydrogenase type 2 activity converting cortisol to cortisone. Although the concentration of plasma cortisol is elevated during pregnancy, the diurnal pattern is preserved $(8,18)$.

Increased placental vasopressinase activity is counterbalanced by increased pituitary vasopressin release in normal pregnancy but may manifest as transient diabetes insipidus or unmask incipient diabetes insipidus (19).

\section{Methods}

\subsection{Guideline working group}

These guidelines were developed on behalf of The European Society of Endocrinology (ESE), the chairs of the working group Anton Luger and Olaf Dekkers being appointed by the ESE Clinical Committee. Olaf Dekkers served as methodological expert, Beverly MK Biller as representative of the Endocrine Society, USA, Rasa Verkauskiene as European Society for Paediatric Endocrinology (ESPE) representative, Sofia Llahana as ESE Nurses representative, Nienke Biermasz as European Neuroendocrine Association (ENEA) representative, Susan Webb as European Reference Network on Rare Endocrine Conditions (ENDO-ERN) representative, Fahrettin Kelestimur as Pituitary Society representative and Gesthimani Mintziori as European Young Endocrinologists and Scientists (EYES) representative. The other members were suggested by the chairs and approved by the Clinical Committee of ESE. The multidisciplinary team consisted of the following experts: endocrinologists Anton Luger (Austria), Olaf Dekkers (the Netherlands), Jens Otto Jorgensen (Denmark), Philippe Chanson (France), Dominique Maiter (Belgium), Fahrettin Kelestimur (Turkey), Beverly MK Biller (USA), Susan Webb (Spain), Nienke Biermasz (the Netherlands), and Gesthimani Mintziori (Greece), an endocrine nurse Sofia Llahana (UK), an obstetrician and gynaecologist Felice Petraglia (Italy), a neurosurgeon Michael Buchfelder (Germany), and a paediatric endocrinologist Rasa Verkauskiene (Lithuania). Leonie Broersen joined the guideline working group for methodology support. The working group had two in-person meetings (February 2019 and November 2019) and communicated by phone and email. Consensus was reached upon discussion; minority positions were taken into account in the rationale behind recommendations. Prior to the process, all participants completed conflict of interest forms.

\subsection{Target group}

This guideline was developed for health care providers who may see pregnant patients with pituitary adenomas. In general, these women (with the exception of those with small nonfunctioning adenomas and microprolactinomas) should preferably be managed by a multidisciplinary team in expert pituitary centers, including Pituitary Tumor Centers of Excellence (PTCOE) (20)/Endo-ERN Reference Centers and their affiliated regional healthcare providers. General practitioners and patients might also find the guideline useful. The guideline can serve as a source document for the preparation of patient information leaflets and educational materials.

\subsection{Aims}

The purpose of this guideline is to provide clinicians with practical guidance for the management of patients with a pituitary adenoma during pregnancy or considering pregnancy. In clinical practice, both the recommendations and the clinical judgement of the treating physician should be taken into account. Recommendations are not meant to replace clinical acumen. Certain recommendations may not be feasible in individual countries and must be interpreted in the context of available resources.

\subsection{Summary of methods used for guideline development}

Themethodsused for establishing such guidelines havebeen described in detail previously (21). In short, the guideline used GRADE (Grading of Recommendations, Assessment, Development, and Evaluation) as a methodological basis. The first step was to define clinical questions (see Section 3.5); the second step was a systematic literature search (see Section 3.6). After including all relevant articles for each clinical question, we rated the quality of the evidence and estimated an average effect for specific outcomes where possible. The quality of the evidence behind the recommendations was classified as very low $(\oplus \circ \bigcirc \bigcirc)$, low $(\oplus \oplus \bigcirc \bigcirc)$, moderate $(\oplus \oplus \oplus \bigcirc)$, or strong $(\oplus \oplus \oplus \oplus)$. Not all recommendations were formally graded (see below).

For the recommendations, we considered the quality of the evidence, the balance of desirable and undesirable outcomes, and individual values and preferences (patient preferences, goals for health, costs, management inconvenience, feasibility of implementation, etc.) $(22,23)$. The recommendations are worded as 
'recommend' (strong recommendation) or 'suggest' (weak recommendation). The meaning of a strong recommendation is that all reasonably informed persons (clinicians, politicians, and patients) would want the management in accordance with the recommendation. For a weak recommendation, most persons would still act in accordance with the guideline, but a substantial number would not (23).

Formal evidence syntheses were performed and graded only for recommendations addressing our initial clinical questions (see Section 3.5). Other recommendations were based on good practice, experience of the panelists and were not formally graded (24). Recommendations were derived from majority consensus of the guideline development committee. Potential disagreements are acknowledged. All recommendations are accompanied by an explanation.

\subsection{Clinical questions, eligibility criteria and endpoint definition}

At the start of this guideline process, the committee members formulated 21 clinical questions regarding diagnosis, treatment, and outcome related to pregnant women with a pituitary adenoma. Out of these 21 clinical questions, the five most relevant questions were prioritised and formed the basis of a systematic literature search and review (Table 2). Discrepancies in results and estimations of our findings compared with previously published reviews $(25,26)$ are mainly due to strict application of inclusion criteria, for example, not including review articles, which also minimises the risk of bias by including the same population multiple times.

\subsection{Description of search and selection of literature}

We searched four electronic medical databases (PubMed, Embase, Web of Science, and COCHRANE). The literature search for questions I-III was performed in July 2019, and the literature search for questions IV and V was performed in September 2019. Additionally, all searches were repeated in PubMed in November 2019, references of included articles were checked to identify potentially relevant additional articles (Fig. 1 and Table 2).

For question I (safety profile of medical treatment of prolactinomas in pregnancy), we identified 1235 papers, 46 were included, 3 were added after searching through the references, and 2 were added in November 2019, for a total of 51 studies. For sub-questions Ia (safety profile of medical treatment of hyperprolactinaemia in pregnancy) and $\mathrm{Ib}$ (safety profile of medical treatment from studies combining data of prolactinoma and hyperprolactinaemia in pregnancy), 26 additional studies were included. For question II (safety profileofmedical treatment of acromegaly in pregnancy), we identified 381 papers, 47 were included. For question III (safety profile of medical treatment of Cushing's disease (CD) in pregnancy), we identified 248 papers, 10 met the inclusion criteria. For question IV (incidence of tumour growth in pregnancy), we included 4 studies on acromegaly, 18 studies on prolactinomas and one on nonfunctioning pituitary adenomas; no studies on $\mathrm{CD}$ could be included. For question $\mathrm{V}$ (safety of pituitary surgery), we included 28 papers. A flow diagram of study inclusion is presented in Fig. 1. For the outcome 'small for gestational age', birth weight and term of pregnancy were compared using population-based reference values from the United States (27).

\subsection{Review process and endorsement of other societies}

A draft of the guideline was reviewed by 4 experts in the field (see 'Acknowledgements' section) and was distributed to all ESE members for comments. In addition, the following societies and networks were asked to review the guidelines: the European Association of Neurosurgical Societies, the Endocrine Society, USA, the European Reference Network on Rare Endocrine Conditions (EndoERN), and the European Neuroendocrine Association (ENEA). Furthermore, patient groups were approached to review the guidelines. All comments and suggestions were then discussed and implemented as thought appropriate by the panel.

\section{Summary and interpretation of the evidence from systematic literature reviews}

\subsection{Clinical question I: What is the safety profile and teratogenicity of medical treatment during pregnancy in patients with prolactinoma?}

We included 51 studies on medical treatment of prolactinomas during pregnancy $(28,29,30,31,32,33,34$, $35,36,37,38,39,40,41,42,43,44,45,46,47,48,49,50,51$, $52,53,54,55,56,57,58,59,60,61,62,63,64,65,66,67,68$, $69,70,71,72,73,74,75,76,77,78)$, and another 26 studies on medical treatment of hyperprolactinaemia (including patients with prolactinomas in mixed populations) 


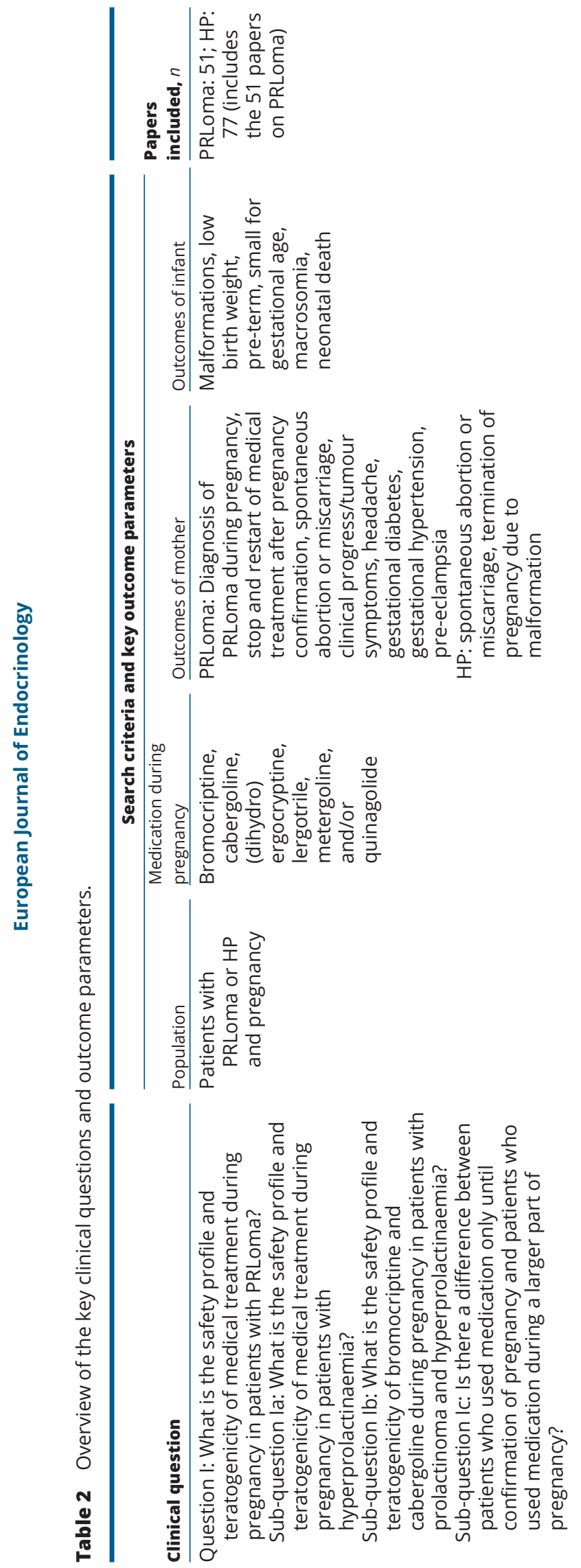

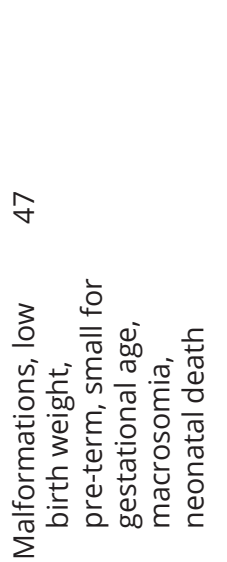

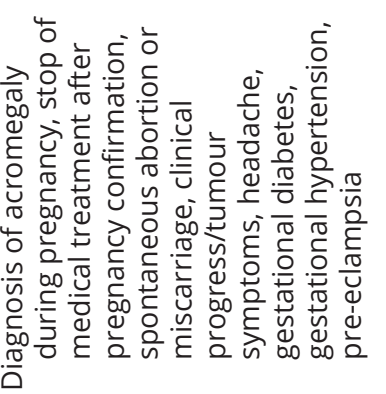

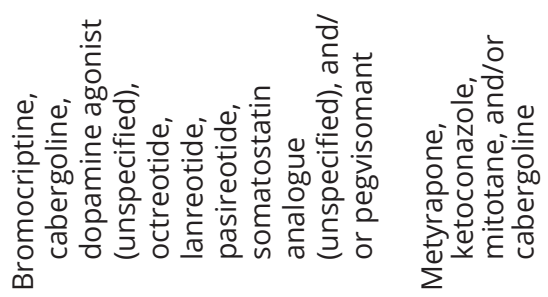

뭄

广⿺

\section{产 它 \\ 突 \\ 竞}

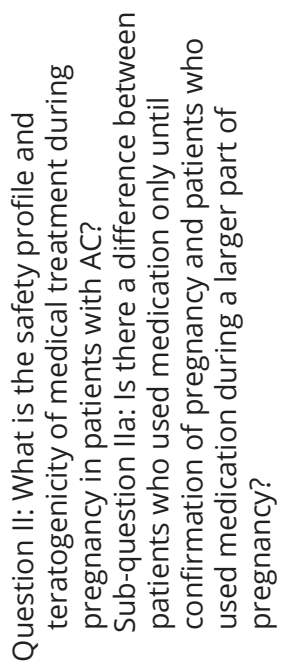

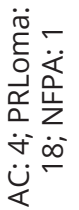

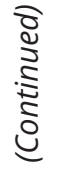
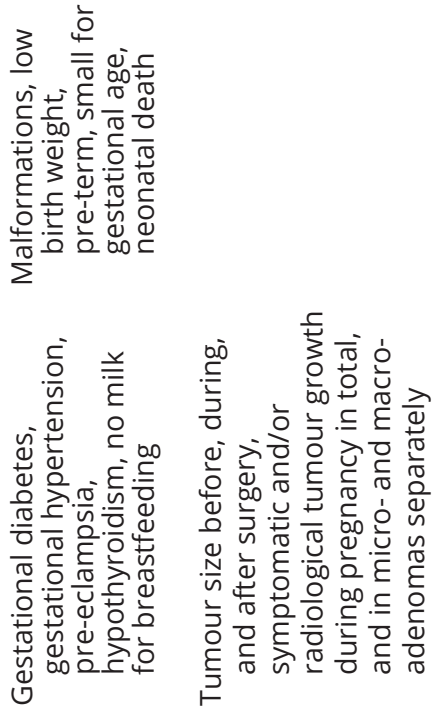
$(79,80,81,82,83,84,85,86,87,88,89,90,91,92,93,94,95$, 96, 97, 98, 99, 100, 101, 102, 103, 104), see Appendix 1 Table 1 (see section on supplementary materials given at the end of this article) for the description of the GRADE evidence and Appendix 1 Table 2 for details of included studies. In total, 837 pregnancies in patients with prolactinoma were included, resulting in 762 live infants. For hyperprolactinaemia from mixed aetiology, the numbers were 2144 pregnancies, resulting in 1873 live infants. Patients used mainly bromocriptine or cabergoline, but also (dihydro)ergocryptine, lergotrile, metergoline, and quinagolide during pregnancy. In the majority of patients with prolactinoma (553 pregnancies), medical treatment was stopped after confirmation of pregnancy $(73.2 \%$, 95\% CI: 69.9-76.4\%). Medical treatment was later restarted during pregnancy in 29 out of these 553 patients $(5.2 \%$, 95\% CI: 3.5-7.4\%). A summary of safety and teratogenicity outcomes is shown in Appendix 1 Table 3. Of note, not all reported maternal events happened during the use of medication for prolactinoma or hyperprolactinaemia. No formal control groups were included, hampering firm conclusions.

There was one reported neonatal death after the use of cabergoline for prolactinoma during pregnancy (no further data on duration or timing of treatment was provided). There were four cases of neonatal death after medical treatment for hyperprolactinaemia during pregnancy, all of whom after treatment with bromocriptine (no further data provided). In women with prolactinomas there were 17 infants with malformations: 6 after the use of bromocriptine, and 11 after the use of cabergoline. Additionally, there were 30 malformations after medical treatment of hyperprolactinaemia during pregnancy: 5 after the use of bromocriptine, and 25 after the use of cabergoline. The data did not indicate a higher prevalence of congenital malformations after the use of the medication for prolactinoma $(2.2 \%, 95 \% \mathrm{CI}: 1.3-3.5)$ or hyperprolactinaemia $(2.5 \%, 95 \% \mathrm{CI}: 1.8-3.3)$ during pregnancy than in the general population $(2.4 \%$ in Europe) (105).

In addition, safety and teratogenicity outcomes did not clearly differ between bromocriptine and cabergoline (see Appendix 1 Table 3). The most commonly reported (maternal) signal was the percentage of patients with symptomatic tumour growth (5.4\%, 95\% CI: 3.9-7.1). Based on our review of tumour growth during pregnancy (see Section 4.4), this was most likely observed predominantly in women with macroadenomas. Often, prolactinoma medication was restarted in these patients to treat symptoms of tumour progression. 


\begin{tabular}{|c|c|c|c|c|c|}
\hline & $\begin{array}{l}\text { Search 1: } \\
\text { Prolactinoma }\end{array}$ & $\begin{array}{l}\text { Search 2: } \\
\text { Acromegaly }\end{array}$ & $\begin{array}{l}\text { Search 3: } \\
\text { Cushing's } \\
\text { disease }\end{array}$ & $\begin{array}{l}\text { Search 4: Growth - } \\
\text { non-functioning } \\
\text { pituitary adenoma }\end{array}$ & $\begin{array}{l}\text { Search 5: } \\
\text { Transsphenoidal } \\
\text { adenomectomy }\end{array}$ \\
\hline & $\downarrow$ & $\downarrow$ & $\downarrow$ & $\downarrow$ & $\downarrow$ \\
\hline \multirow[t]{2}{*}{ Potentially relevant articles } & 1235 & 381 & 248 & 82 & 1774 \\
\hline & $\downarrow$ & $\downarrow$ & $\downarrow$ & $\downarrow$ & $\downarrow$ \\
\hline \multicolumn{6}{|l|}{ Articles excluded: } \\
\hline - No original data & 463 & 138 & 130 & 29 & 469 \\
\hline - Wrong population & 294 & 110 & 77 & 15 & 473 \\
\hline - No pregnancy & 151 & 29 & 14 & 9 & 191 \\
\hline - No treatment during pregnancy & 60 & 4 & 8 & - & 420 \\
\hline - No relevant outcome & 119 & 6 & 3 & - & - \\
\hline - No separate outcome for & 65 & - & 1 & - & 1 \\
\hline - Language not known by & 7 & 1 & - & - & 2 \\
\hline - No human subjects & 18 & 44 & 5 & 6 & 186 \\
\hline - Duplicate & 11 & 2 & - & - & 3 \\
\hline - $\mathrm{N}<10$ & - & - & - & 22 & - \\
\hline \multirow[t]{2}{*}{ - No full-text available } & 1 & 1 & - & - & 1 \\
\hline & $\downarrow$ & $\downarrow$ & $\downarrow$ & $\downarrow$ & $\downarrow$ \\
\hline Articles included from search & 46 & 46 & 10 & 1 & 28 \\
\hline Added from references & 3 & - & - & - & - \\
\hline \multirow[t]{2}{*}{ Added in November 2019} & 2 & 1 & - & - & - \\
\hline & $\downarrow$ & $\downarrow$ & $\downarrow$ & & \\
\hline Articles included in question $1 a+b$ & 25 & - & - & & \\
\hline Added from references (q.1a+b) & 1 & - & - & & \\
\hline Articles included in question 4 & 18 & 4 & - & & \\
\hline
\end{tabular}

Figure 1

Flow diagram of study inclusion.

\subsection{Clinical question II: What is the safety profile and teratogenicity of medical treatment during pregnancy in patients with acromegaly?}

We included 47 studies on medical treatment for acromegaly during pregnancy $(55,106,107,108,109,110$, $111,112,113,114,115,116,117,118,119,120,121,122,123$, $124,125,126,127,128,129,130,131,132,133,134,135$, $136,137,138,139,140,141,142,143,144,145,146,147$, $148,149,150,151$ ), see Appendix 2 Table 1 for the GRADE evidence and Appendix 2 Table 2 for study details. In total, 146 patients were included, who had 159 pregnancies, resulting in 159 live infants. Patients used bromocriptine, cabergoline, unspecified dopamine agonists, octreotide, lanreotide, pasireotide, unspecified somatostatin analogues, or pegvisomant during pregnancy. A summary of safety and teratogenicity outcomes after medical treatment for acromegaly during pregnancy is shown in Appendix 2 Table 3. Importantly, not all reported maternal events occurred during the use of medication for acromegaly, as patients may have used the drugs for a shorter period. We performed subgroup analyses of patients using medication until pregnancy confirmation only, and of patients using medication during a larger part of pregnancy, that is also after pregnancy was confirmed.

In 79 pregnancies $(71 \%)$, medical treatment for acromegaly was stopped after confirmation of pregnancy. There was one ectopic pregnancy during use of pegvisomant (146). There was one neonatal death from a pair of twins born after 28 weeks of pregnancy after the use of lanreotide (111). There were two malformations reported: a ureteral stenosis after octreotide LAR $(2.6 \%$ out of 38 octreotide users, 95\% CI: $0.1-13.8 \%$ ), and a single kidney after bromocriptine use. There was no indication from the data that congenital malformations are more prevalent after the use of medication for acromegaly during pregnancy $(1.3 \%$, 95\% CI: $0.2-4.5)$ than in the general population $(2.4 \%$ in Europe) (105). There was no clear difference in safety 
or teratogenicity between patients who used medication until confirmation of pregnancy only and patients who used medication during a longer period of pregnancy.

\subsection{Clinical question III: What is the safety profile and teratogenicity of medical treatment during pregnancy in patients with Cushing's disease?}

We included 10 studies, reporting on 10 women, with medical treatment for Cushing's disease during pregnancy $(152,153,154,155,156,157,158,159,160,161)$, some of which also involved patients with cortisol secreting adrenal adenomas. The GRADE evidence table is shown in Appendix 3 Table 1, and details of the studies are shown in Appendix 3 Table 2. Patients used metyrapone, ketoconazole, mitotane, and cabergoline during pregnancy. Adverse effects were reported in six out of ten mothers (60\%, 95\% CI: 26-88\%): gestational diabetes mellitus, pre-eclampsia, hypothyroidism, no milk for breastfeeding. Seven out of 12 infants (two pairs of twins) experienced adverse events (one neonatal death; low birth weight, small for gestational age, pre-term, intensive care treatment), which is $58 \%$ (95\% CI: $28-85 \%$ ). There were no congenital malformations reported. Numbers are too small to draw firm conclusions on preferred treatment and teratogenicity, based on published data.

\subsection{Clinical question IV: What is the incidence of tumour growth during pregnancy in patients with a nonfunctioning or functioning (Cushing's disease, acromegaly, or prolactinoma) adenoma?}

We included one study on tumour growth during pregnancy in nonfunctioning pituitary adenomas $(162)$, 18 studies in patients with prolactinoma $(44,46,51$, $52,55,57,64,71,72,76,78,80,162,163,164,165,166$, $167)$, and four studies in patients with acromegaly (55, 110, 119, 124); see Appendix 4 Table 1 for the GRADE evidence, and Appendix 4 Table 2 for details of included studies. Not all studies differentiated between micro- and macroadenomas. For nonfunctioning pituitary adenoma, the only study reported on 16 pregnancies in 16 patients; for prolactinoma, studies reported on 753 pregnancies in 652 patients, with separate data on 146 microadenomas and 162 macroadenomas. For acromegaly, there were 128 pregnancies in 97 patients, with separate data on 17 microadenomas and 106 macroadenomas. There were no reported Cushing's disease cases.
Average tumour size before and after pregnancy was compared in four studies that showed unchanged (46), increased $(80,162)$, or reduced adenoma size (76). For nonfunctioning pituitary adenomas, symptomatic tumour growth (headache or visual defects) occurred in six patients (37.5\%, 95\% CI: 15.2-64.6\%) and radiologically confirmed tumour growth as defined by the individual studies was seen in four patients $(25.0 \%, 95 \% \mathrm{CI}$ : 7.3-52.4\%). In prolactinoma, symptomatic tumour growth during pregnancy was seen in 52 patients $(9.0 \%$, 95\% CI: 6.8-11.6\%) and radiological tumour growth in 40 (10.6\%, 95\% CI: 7.7-14.2\%). For microprolactinomas, there were seven patients with symptomatic tumour growth $(15.2 \%, 95 \%$ CI: 6.3-28.9\%) and 15 with radiological tumour growth (14.4\%, 95\% CI: 8.3-22.7\%). For macroprolactinomas, there were 36 patients with symptomatic tumour growth (30.5\%, 95\% CI: 22.4-39.7\%) and 19 with radiological tumour growth (13.9\%, 95\% CI: 8.6-20.8\%). In acromegaly, symptomatic tumour growth during pregnancy was seen in nine patients $(7.0 \%, 95 \% \mathrm{CI}$ : $3.3-12.9 \%)$ while radiological tumour growth occurred in six $(5.4 \%$, 95\% CI: 2.0-11.4\%). For GH-producing microadenomas, three patients exhibited symptomatic tumour growth (30.0\%, 95\% CI: 6.7-65.2\%), and two only radiological tumour growth (25.0\%, 95\% CI: 3.2-65.1\%); however, the low number of patients precludes a firm conclusion regarding the true risk as can be seen from the wide CIs. For GH-producing macroadenomas, there were four patients with symptomatic tumour growth $(4.1 \%$, 95\% CI: 1.1-10.2\%), and three with radiological tumour growth (3.7\%, 95\% CI: 0.8-10.3\%).

\subsection{Clinical question V: Is pituitary surgery safe for pituitary adenomas during pregnancy?}

We included 28 studies on transsphenoidal surgery of pituitary adenomas during pregnancy $(28,49,124,135$, $153,157,168,169,170,171,172,173,174,175,176,177,178$, $179,180,181,182,183,184,185,186,187,188,189)$, see Appendix 5 Table 1 for the GRADE evidence, and Appendix 5 Table 2 for study details. Pituitary surgery was performed in 33 cases during pregnancy. The vast majority of patients had hormone secreting macroadenomas (Appendix 5 Table 2). Surgery was performed during the first $(n=2)$, second $(n=24)$ and third $(n=7)$ trimester. The indications for surgery mainly included active Cushing disease, visual deterioration related to tumour growth or apoplexy. Surgery provided symptom relief in 25 cases out of 28 in 
whom effectiveness was reported (89.3\%, 95\% CI: 71.8$97.7 \%)$. In total, nine women experienced surgery-related adverse events (diabetes insipidus, SIADH, cerebrospinal fluid leakage). This high percentage of adverse events might be related to the special indication for pituitary surgery in pregnancy being restricted to emergency situations. In total, nine infants showed adverse outcomes in the course of pregnancy (28.1\%; 95\% CI: 13.7-46.7\%). There was one miscarriage soon after surgery during the second trimester. Furthermore, there was one intrauterine death, and two cases of neonatal death not directly after surgery. Most adverse outcomes for infants occurred in mothers with Cushing's disease (eight out of nine infants with adverse events).

\section{Recommendations and rationale for the recommendations}

\subsection{General recommendations: Pre-conception stage}

R.1.1. We recommend that women of reproductive age with a diagnosis of a pituitary adenoma be counselled about their potential fertility and pregnancy outcomes as early as possible.

\section{Rationale}

Pituitary function might be impaired due to compression by or hormonal hypersecretion from the pituitary adenoma. In addition, side effects of medical therapy for the mother and foetus should be taken into account and discussed with women of reproductive age. In women with hypopituitarism, replacement therapy should be optimised, and assisted reproductive technologies (ART) should be discussed when appropriate. Women should be given relevant information about their chances of fertility and pregnancy depending on their diagnosis (see respective recommendations for each adenoma). Timing of pregnancy should be discussed and women should be encouraged to plan pregnancy after control of the underlying disease has been achieved. If unplanned pregnancy occurs, immediate consultation should take place with a team that should include an endocrinologist, an obstetrician with expertise in managing high-risk pregnancies for maternal indications and, in case of large pituitary adenomas, a dedicated pituitary neurosurgeon.

R.1.2. We recommend that women of reproductive age with a diagnosis of pituitary adenoma, functioning or nonfunctioning, who consider pregnancy, be managed by an endocrinologist.

\section{Rationale}

The consulting endocrinologist should inform women seeking pregnancy that this is feasible in the majority of cases, that the outcome is generally good and that breast feeding is often possible (see respective recommendations for the different adenoma types and therapies). At the same time, it should be stressed that pregnancy constitutes a medical situation where expert knowledge and often collaboration between specialists from different fields is required. The woman's age is a major determinant of fertility and pre-conception counselling should also include an obstetrician with expertise in maternal-fetal medicine and reproductive medicine. An endocrine work-up including all anterior pituitary functions should be performed (see Table 3), with special attention to possible associated metabolic or cardiovascular diseases.

R.1.3. We recommend that management of women of reproductive age with a large pituitary adenoma $(>1 \mathrm{~cm})$, Cushing's disease or acromegaly, who consider pregnancy, be discussed in a multidisciplinary team.

\section{Rationale}

Due to possible compressive effects of macroadenomas, which may enlarge during pregnancy and possible adverse effects of therapies necessary to control size or function of pituitary adenomas, we advise discussing such patients in

Table 3 Work-up when pregnancy is considered.

Medical history with special attention to pituitary condition and its associated comorbidities

Physical examination including BMI calculation and blood pressure

Routine laboratory values including electrolytes, glucose, liver and kidney function tests, lipids, urine dipstick

Representative evaluation of pituitary hormone status (overproduction and deficiency), and reproductive status Consider: Early morning cortisol, ACTH, fT4, TSH, E 2 , LH, $\mathrm{FSH}$, progesterone (on day 21 of menstrual cycle), SHBG, PRL, IGF-I, DHEA-S, testosterone, AMH (on day 3 of menstrual cycle)*

Representative tumour volume status, with dedicated pituitary MRI depending on initial size (macroadenoma) and time since last evaluation

Representative neuro-ophthalmological evaluation if clinically indicated (depending on size and location of the lesion, especially if it is in contact with the optic chiasm)

*Anti-Muellerian hormone (AMH) plasma concentrations are underestimated in hypogonadotropic hypogonadism (190). 
a multidisciplinary team including an endocrinologist, an obstetrician, a pituitary neurosurgeon and in some cases a neuroradiologist, a neuro-ophthalmologist and a reproductive endocrinologist. Compression of the optic chiasm with visual field impairment is an indication for pre-pregnancy pituitary surgery, a tumour in close vicinity to the optic chiasm is a possible indication for surgery. For women with a nonfunctioning pituitary macroadenoma and no visual field impairment, who are seeking pregnancy, the decision to operate prior to planned pregnancy may also take into account the presence of gonadotrophin deficiency (191) as surgery provides pituitary recovery in about $30 \%$ of cases $(192,193)$, in particular normalisation of ACTH, cortisol and PRL (194). The surgical risk of a postoperative gonadotrophin deficiency and also a panhypopituitarism (14\% (195)), which could impact on pregnancy course should be considered, and should be taken into account for the surgical decision.

R.1.4. We recommend that in women with a diagnosis of pituitary adenoma and hypopituitarism, hormone replacement therapy should be initiated or optimised prior to becoming pregnant.

\section{Rationale}

In women with hypopituitarism, reported fertility rates range from 47 to $76 \%$, and reached over $80 \%$ in women with isolated hypogonadotropic hypogonadism after ART $(196,197)$. Women with childhood onset of hypopituitarism have much lower fertility rates $(196,197$, 198, 199).

The pre-conception consultation should include diagnosis of any pituitary deficiencies (see R.1.2.), initiation and optimisation of the replacement therapy aiming for mid-normal reference range values. The importance of adherence to treatment should be emphasised in relation to pregnancy outcomes and foetal health. Women with hypopituitarism and optimal replacement therapy often require ART $(196,200,201)$, but in the absence of gonadotrophin deficiency they may conceive spontaneously $(201,202)$. Initiation and optimisation of GH replacement for at least 3 months prior to conception has been shown to improve the success rate of ART and ovulation stimulation (OS) in women with concomitant gonadotrophin deficiency $(199,203,204,205)$. Even though pituitary hormone deficiency beyond gonadotropins has been correlated with reduced pregnancy rate and outcome, patients with hypopituitarism can be reassured that in vitro fertilisation (IVF) treatment is often successful (206).
Pituitary apoplexy occurring after the application of triptorelin, a GnRH analogue used for OS, has been described $(207,208)$, possibly due to previously undetected gonadotropinomas. It should be highlighted that although fertility outcomes and pregnancy rates for women with hypopituitarism are generally good, studies have shown that women require multiple OS and/or ART cycles to achieve a live birth and the 'take home baby rate' per cycle remains reduced $(197,201,209)$.

\subsection{General recommendations: Pregnancy}

R.2.1. We recommend that pregnant women with known pituitary adenoma, in particular those with a large pituitary adenoma $(>1 \mathrm{~cm})$, Cushing's disease or acromegaly, and those with pituitary deficiencies, should be followed by an endocrinologist and an advanced nurse practitioner where relevant. The frequency depends on the underlying condition and individualised needs.

\section{Rationale}

Pituitary adenomas may cause hypopituitarism, visual impairment or nerve palsies during pregnancy and therefore need special surveillance by an expert endocrinologist. Individualised management is needed throughout pregnancy, the frequency of consultations is determined by the clinical situation, and in uneventful cases, consultations can be limited. In patients with acromegaly and Cushing's disease, special attention to glucose homeostasis and blood pressure is needed. Patients with a microprolactinoma or a nonfunctioning microadenoma will only need consultation with an endocrinologist during pregnancy if new symptoms such as headache or visual symptoms occur.

R.2.2. We recommend that pregnant women with diagnosed hypopituitarism should have regular clinical and hormonal follow-up by an endocrinologist and an advanced nurse practitioner where relevant.

\section{Rationale}

Women with pituitary adenomas and hypopituitarism require regular follow-up at least every trimester to monitor for adequate substitution doses and/or to identify signs or symptoms of any newly developed pituitary insufficiencies or complications associated with functioning adenomas, mainly GH or ACTH-producing $(196,200,210,211)$. 
Patients on levothyroxine replacement therapy might require an increase in dose of up to $50 \%(11,12)$. Free T4 levels should be used for monitoring, rather than TSH, which is not reliable in patients with pituitary disorders $(11,212)$. Adequate dose should be checked during the first and second trimesters using gestational phase- and assayspecific reference values (13). Whereas an interval of 4-6 weeks has been suggested for fT 4 measurement throughout pregnancy (200), not all members of this Clinical Guideline Committee monitor their patients that frequently.

In women with adrenal insufficiency, there is usually no need to alter the doses of glucocorticoid replacement therapy during the first half of pregnancy, but an increase by $20-40 \%$ may be needed from week 22 to 24 onwards, since free cortisol increases during this period in healthy women. Hydrocortisone is the preferred choice for glucocorticoid replacement during pregnancy; prednisone is also an option as it does not cross the placenta. Only $10-12 \%$ of the maternal prednisolone concentration reaches the foetus (213). Dexamethasone should be avoided because it is insufficiently inactivated by placental $11 \beta-H S D 2$ and may therefore cause harm to the foetus (196, 200, 210, 211, 214).

The desmopressin dose might need to be increased during the third trimester due to placental vasopressinase activity and the patient should be informed that in case of polyuria and increase of desmopressin, serum sodium concentration should be checked to avoid hyponatraemia. Administration of desmopressin appears to be otherwise safe in pregnancy $(19,215)$.

GH replacement is usually stopped after conception or by the end of the first trimester; the benefit-risk balance for GH in pregnancy cannot be assessed $(196,200)$. Furthermore, large amounts of GH are secreted by the placenta during pregnancy. One large observational study revealed no relationship between GH replacement therapy regimens and pregnancy outcomes (216).

R.2.3. We recommend that women and their partners be provided with education for glucocorticoid stress dose adjustment and measures on how to prevent or manage adrenal crisis during pregnancy.

\section{Rationale}

Symptoms such as persistent nausea, hyperemesis, and excessive fatigue are common in pregnancy. These can also be triggers or symptoms of the onset of an adrenal crisis and vigilance is therefore mandated. Patient and partner education regarding stress-coverage dosage of hydrocortisone (sick day rules), access to a hydrocortisone injection kit and glucocorticoid emergency card, and training on self-injecting are crucial to prevent and promptly manage an adrenal crisis. In case of an adrenal crisis, fluid replacement (best with $0.9 \%$ saline IV) and immediate parenteral administration of hydrocortisone $100 \mathrm{mg}$ (IV, IM, SC) are potentially life-saving for the mother $(200,210,214,217)$. Fetal monitoring by cardiotocography (CTG) and ultrasound is also necessary to ensure the wellbeing of the unborn child.

R.2.4. We recommend performing an MRI without contrast in pregnancy in case of symptoms of tumour progression or apoplexy.

\section{Rationale}

MRI is considered safe in pregnancy and should be used in symptomatic patients with impairment of visual fields or visual acuity, cranial nerve palsies or severeheadacheusually after neuro-ophthalmologic evaluation. Gadolinium can cross the placenta and reach the foetal circulation $(218,219$, $220,221)$, its use is therefore to be avoided in most cases, especially in the first trimester. Relevant information can usually be obtained by unenhanced T1 and T2 weighted sequences. Routine MRI follow-up during pregnancy is not recommended.

R.2.5. We recommend that neuro-ophthalmologic examination in pregnancy be performed for adenomas impinging visual pathways or in case of suspected tumour progression or pituitary apoplexy.

\section{Rationale}

Due to the possible risk of tumour impingement of the visual pathways, a neuro-ophthalmologic evaluation including determination of visual acuity, visual fields and, if available, optical coherence tomography (OCT) analysing retinal nerve fibre layer (RNFL) and ganglion cell complex (GCC) should be performed in symptomatic patients, which will aid the decision about whether a MRI is indicated. Women with pituitary adenomas larger than $1 \mathrm{~cm}$ not previously treated with surgery or radiotherapy are at increased risk of visual field impairment during pregnancy (222). Together with the results of endocrine function and MRI, the neuro-ophthalmologic evaluation will guide the need for further action. The frequency of neuro-ophthalmologic 
evaluations will be determined by signs and symptoms as well as by results of prior examinations.

R.2.6. We recommend considering surgery in pregnant women with deterioration of vision, ophthalmoplegia or severe headache attributable to tumour enlargement if medical tumour treatment is unfeasible or ineffective $(\oplus \oplus \circ)$.

\section{Rationale}

In situations with chiasmal compression and severe loss of vision (impairment of visual acuity or OCT or severe visual field impairment) surgical decompression should be considered even if there is no detectable radiological enlargement of the tumour $(191,223,224)$. Surgery provided symptom relief in $89.3 \%$ (95\% CI: 71.8-97.7\%), see 4.5 for details. In case of other cranial nerve palsies or headache occurrence, particularly related to apoplexy, surgical resection should be individually discussed.

R.2.7. If surgery is indicated, we suggest to perform transsphenoidal surgery in the second trimester if the clinical course allows this $(\oplus \oplus \bigcirc)$ ).

\section{Rationale}

Surgical indications for pituitary tumours are rare during pregnancy and surgery should generally be avoided. In cases of symptomatic tumour enlargement during pregnancy, medical treatment with dopamine agonists or somatostatin analogues may be attempted before undertaking transsphenoidal surgery. Severe visual disturbance related to pituitary apoplexy or tumour growth, and uncontrolled Cushing's disease are the main surgical indications during pregnancy.

There are no guidelines on transsphenoidal surgery in pregnancy. Evidence comes from small series (see Section 4.5) (223). The majority of cases published had surgery in the second trimester. The first trimester should be avoided if possible $(225,226)$. In the third trimester, preterm delivery before non-obstetrical surgery should be considered. Emergency operations (e.g. severe loss of vision or ophthalmoplegia) must be considered and performed at any time during pregnancy preferably in expert pituitary centres, including Pituitary Tumor Centers of Excellence/ Endo-ERN Reference Centers. The abovementioned statements are supported by the neurosurgical literature on meningioma management during pregnancy $(223,227)$.
R.2.8. We recommend not to perform radiotherapy during pregnancy.

\section{Rationale}

Radiotherapeutical interventions are inappropriate during pregnancy due to their delay in the onset of effects and potential harm to the foetus.

\subsection{General recommendations: Delivery and breastfeeding}

R.3.1. We suggest that pregnant women with pituitary adenomas should receive standard obstetrical care but recommend close maternal and foetal surveillance.

\section{Rationale}

A systematic review of 31 pregnancy outcomes in women with hypopituitarism found no neonatal complications or congenital anomalies in the newborns. However, these women had higher rates of caesarean deliveries, transverse lie and small for gestational age neonates compared to controls (228). A recent study showed that women with nonfunctioning adenomas were more likely to have Caesarean delivery compared to controls (relative risk 2.06, 95\% CI: 1.26-3.36). There was no solid evidence that pituitary tumours were associated with adverse pregnancy outcomes such as pregnancy-induced hypertension, preeclampsia, pre-term labour or still birth (162). Women should be informed early on in their pregnancy about the possibility of Caesarean delivery.

Special monitoring of the newborns for the risk of hypoglycaemia is needed in case of maternal hyperglycaemia and/or hypertension, disorders that may occur in GH and ACTH secreting pituitary adenomas (110). In rare pregnancies with Cushing's disease, the risk for prematurity and intrauterine growth restriction is elevated and there were individual reports of coarctation of the aorta, transient neonatal jaundice, hypoglycaemia and adrenal insufficiency requiring temporary treatment with hydrocortisone (157).

In women with ACTH deficiency, hydrocortisone stress dosing is recommended during labour, similar to that used in major surgical stress. Hydrocortisone 100 mg intravenously should be initiated at the onset of active labour for vaginal delivery or pre-operatively for a Caesarean section. While it has been suggested that 
this should be followed immediately by a continuous intravenous infusion of hydrocortisone $200 \mathrm{mg} / 24 \mathrm{~h}$ throughout labour for both vaginal delivery or Caesarean section $(200,210,229)$, most members of this Clinical Guideline Committee are using lower doses. After delivery, the pregnancy hydrocortisone dose should be gradually tapered down to the pre-pregnancy dose (200, 210, 214, 217).

R.3.2. In general, breastfeeding is feasible and not contraindicated.

\section{Rationale}

Individual concerns such as the need to control tumour size and activity as well as type of drug therapy employed need to be considered, please see specific chapters and list of drugs used for the treatment of pituitary adenomas (Appendix 6).

\subsection{Nonfunctioning adenomas (NFAs)}

In women with NFAs diagnosed prior to pregnancy, the general recommendations for the pre-conception stage, pregnancy, delivery and breastfeeding apply (see Chapters 5.1-5.3).

R.4.1. In women with a NFA near the optic chiasm who are planning a pregnancy, surgery may be considered to reduce the risk of chiasmal compression and to enhance fertility.

\section{Rationale}

As the pituitary gland expands during pregnancy, surgery should be considered on the basis of NFA size and proximity to the optic pathways (see R.1.3.). Additionally, it has been suggested that for women with a macroadenoma and no visual field impairment, who plan pregnancy, surgery may be considered in order to optimize fertility (191), since surgery provides recovery of hypopituitarism in about $30 \%$ (192). The risk of postoperative pituitary deficiency, which is estimated around 14\% (195) should be integrated in the surgical decision particularly in case of normal preoperative pituitary function.

R.4.2. We suggest that for women with intrasellar nonfunctioning microadenomas and an uneventful pregnancy, there is no need for routine endocrinological follow-up during pregnancy.

\section{Rationale}

The majority of previously treated NFAs do not enlarge during pregnancy $(55,162,222)$. A study monitored 65 women with treatment naïve pituitary adenomas during 111 pregnancies; none of the patients with a microadenoma developed visual impairment after up to four full-term pregnancies (222). Additionally, new-onset pituitary hormone deficiencies are unlikely.

R.4.3. We recommend that for macroadenomas and/or extrasellar NFAs, neuro-ophthalmologic and, if indicated, MRI examination should be performed only in case of symptoms of tumour progression or pituitary apoplexy during pregnancy.

\section{Rationale}

In contrast to microadenomas, six of eight primiparous patients with macroadenomas (range $1.2-2.5 \mathrm{~cm}$ ) in the above-mentioned study developed visual field impairment (222). In case of macroadenomas in contact or close to the chiasm, systematic visual examination should be considered. Visual examination frequency and type of tests (with or without optical coherence tomography) depend on the local practices and should be adapted caseby-case.

R.4.4. We recommend that in case of a clinical need to reduce adenoma volume during pregnancy, surgery is the preferred option $(\oplus \bigcirc \bigcirc)$ ).

\section{Rationale}

The main indication for pituitary surgery during pregnancy is to protect visual function $(191,223,224)$. A trial with cabergoline might be considered. Apoplexy is another rare but acute condition in a patient with NFA that may require surgical intervention. If possible, the first trimester should be avoided and in the third trimester pre-term delivery should be considered (see R.2.7.).

R.4.5. We recommend awaiting reassessment of pituitary imaging and function until after delivery and breastfeeding.

\section{Rationale}

A de novo radiological diagnosis of a pituitary mass lesion during pregnancy is usually based on symptomatic visual field defects and/or pituitary apoplexy. Before making a 
NFA diagnosis, other diagnoses should be excluded, for example, CD, acromegaly, prolactinomas, hypophysitis. Reassessment of pituitary imaging and function should be done between 3 and 6 months after delivery, preferably after breastfeeding but definitely before planning a following pregnancy, unless the clinical picture suggests otherwise.

\subsection{Prolactinomas}

A prolactinoma is expected to be present in 1/500 women of reproductive age (230) and is frequently associated with infertility $(25,231)$. Very high prolactin levels will usually cause amenorrhoea, while milder degrees of hyperprolactinaemia may cause oligomenorrhoea or luteal phase insufficiency (232). Furthermore, in the presence of regular cycles, abnormal prolactin concentrations might alter hormonal conditions for adequate embryo implantation (230).

R.5.1. We recommend treating women with a prolactinoma, who are actively seeking pregnancy, with a dopamine agonist and strive for normalisation of prolactin concentrations and restoration of regular ovulatory cycles $(\oplus \oplus \oplus \bigcirc)$.

\section{Rationale}

In agreement with guidelines from both the Pituitary Society and the Endocrine Society, we consider a desire for pregnancy as an indication for strict prolactin normalisation in young women with a prolactinoma, even in those with mild hyperprolactinaemia and apparently regular normal cycles $(232,233)$. It is important to inform patients that restoration of ovulation and fertility may be immediate when they start dopaminergic treatment, even before normal menses return $(25,234)$ and to counsel patients whether prompt conception is safe.

R.5.2. We recommend medical treatment as first-choice therapy for women with a prolactinoma and actively seeking pregnancy; transsphenoidal surgery can be considered in individual cases $(\oplus \oplus \oplus \bigcirc)$.

\section{Rationale}

Dopamine agonists (DA) are the standard treatment for women in reproductive age with a micro- or a macroprolactinoma, restoring ovulation in $80-90 \%(234,235)$. Few studies have directly compared the currently available
DA in their efficacy to allow gestation (236). We suggest using cabergoline because it is better tolerated and has a higher efficacy than bromocriptine in both normalising prolactin levels $(63,232,237,238)$ and inducing pituitary tumour shrinkage $(232,235,239)$. Transsphenoidal adenomectomy is an option in selected cases $(25,230)$ such as intolerance or resistance to DA or personal preference. It is considered less efficient than medical therapy, leading in expert hands to a sustained normalisation of prolactin levels in $70-80 \%$ of microadenomas, but only in $30-40 \%$ of macroadenomas $(240,241)$. However, in macroprolactinomas $(25,232,233)$ it might reduce the risk of tumour enlargement during a subsequent pregnancy (25) and optimise the chances of prolactin normalisation with subsequent DA treatment (242). The risk of postoperative pituitary deficiency remains very limited $(240,243)$.

R.5.3. We recommend cabergoline as medical treatment at the lowest possible effective dose until pregnancy is confirmed $(\oplus \oplus \bigcirc \bigcirc)$.

\section{Rationale}

Treatment with dopamine agonists should not be withdrawn in women seeking pregnancy and, as discussed above, due to its higher efficacy and better tolerance, cabergoline is considered first choice in this population $(232,235)$.

We performed a systematic review of reports published until 2019 on pregnancies initiated under cabergoline treatment $(n=1272)$, of which some patients used cabergoline during a larger part of pregnancy (see Section 4.1 and Table 4). The observed rates of spontaneous miscarriage (9.0\%), pre-term delivery $(8.0 \%)$ and neonatal malformations (3.3\%) are similar to those reported for bromocriptine and do not clearly deviate from those reported in an age-matched population not on DA therapy $(80,244,245)$. While some follow-up studies of children for up to 12 years after foetal exposure to cabergoline do not suggest an increased risk of developmental and or/ metabolic abnormalities (25, 80, 230), one study with a follow-up of 61 children of up to 16 years reported two children who developed epilepsy (one after distress at birth because of abruptio placentae) and two with a pervasive developmental disorder (83). However, the relationship of such disorders with previous cabergoline exposure cannot be proven.

Regarding the use of quinagolide, the manufacturer's data include 176 pregnancies, in which this drug was given for a median duration of 7 weeks; 24 spontaneous abortions, 1 stillbirth and 9 foetal malformations were 


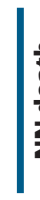

$\underset{\substack{a \\ \mathbf{2}}}{\mathbf{2}}$

$000^{\frac{\alpha}{z}}$ moom-00- $\stackrel{\sim}{\sim}$

000000000000

$000000000-00-5$

000000000000

10
0
0
-0
0
$\vdots 0$

$\stackrel{\text { ๖ं }}{.}$

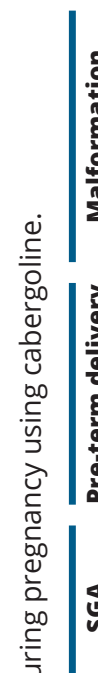

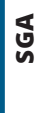

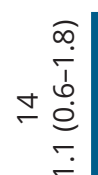

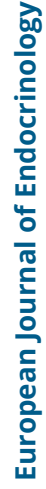

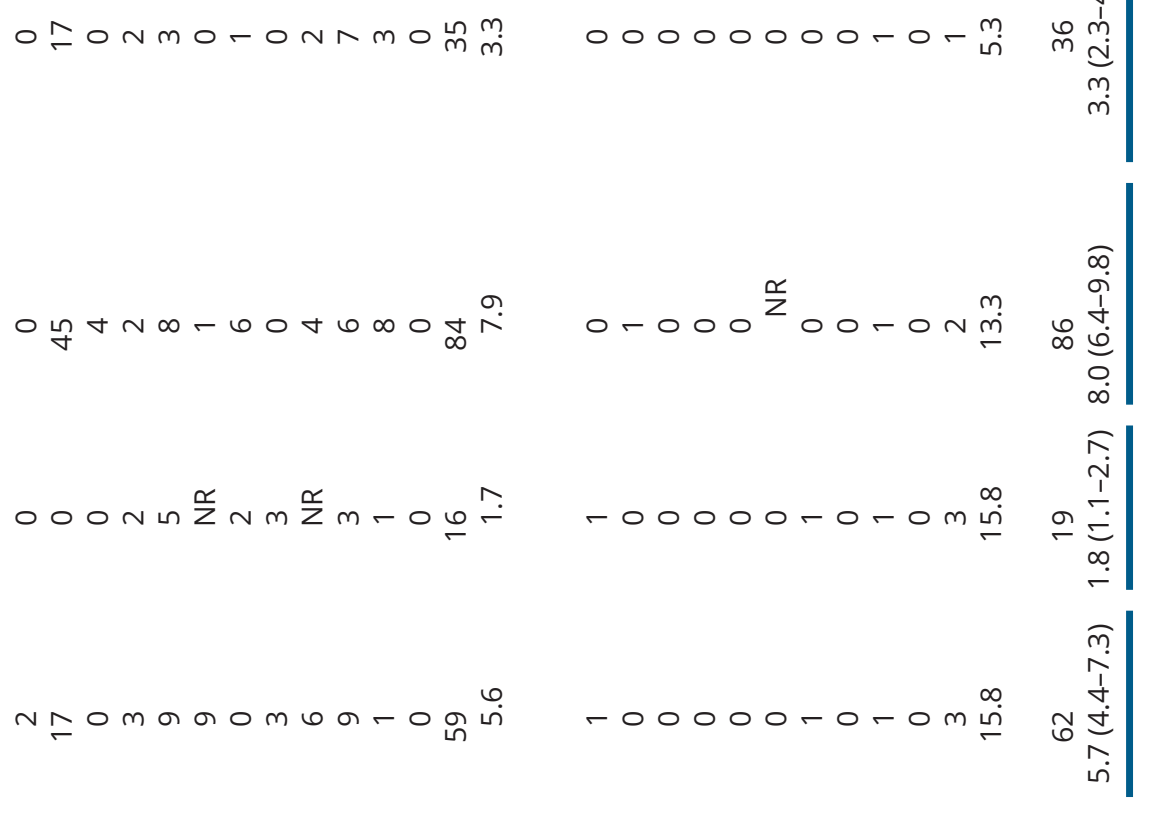

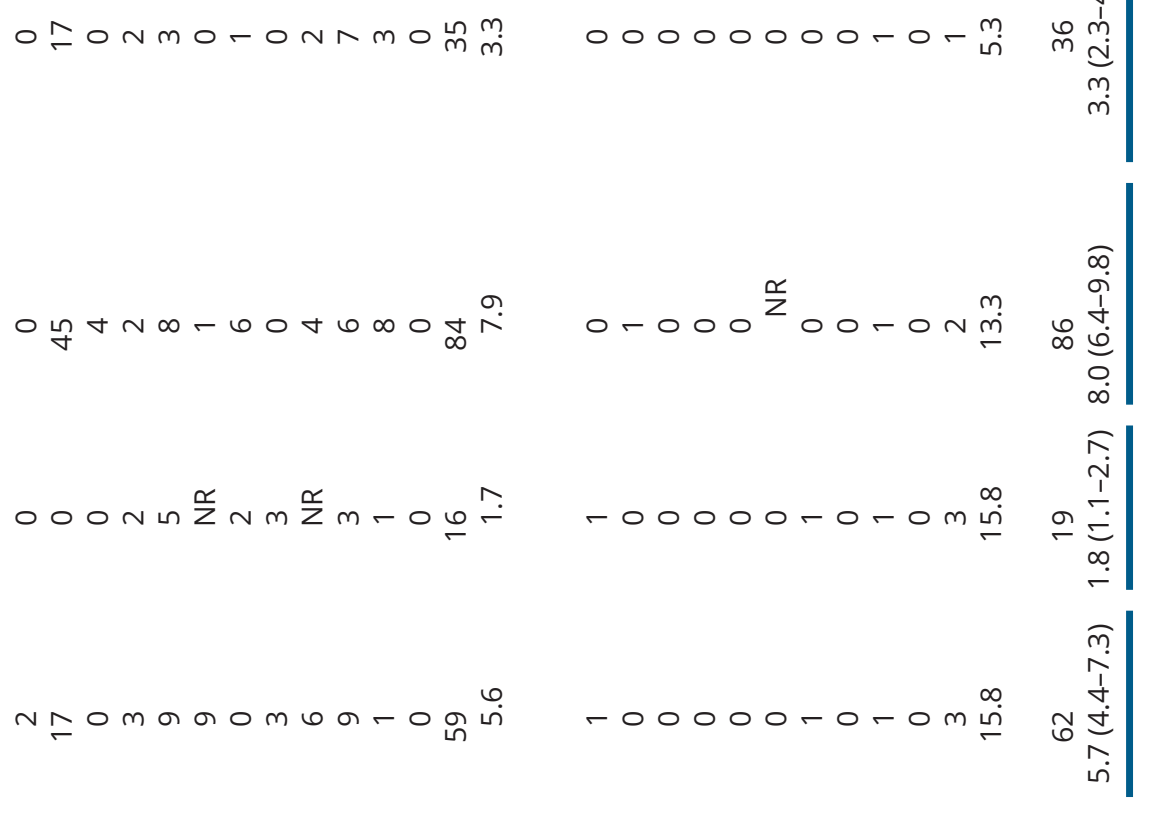

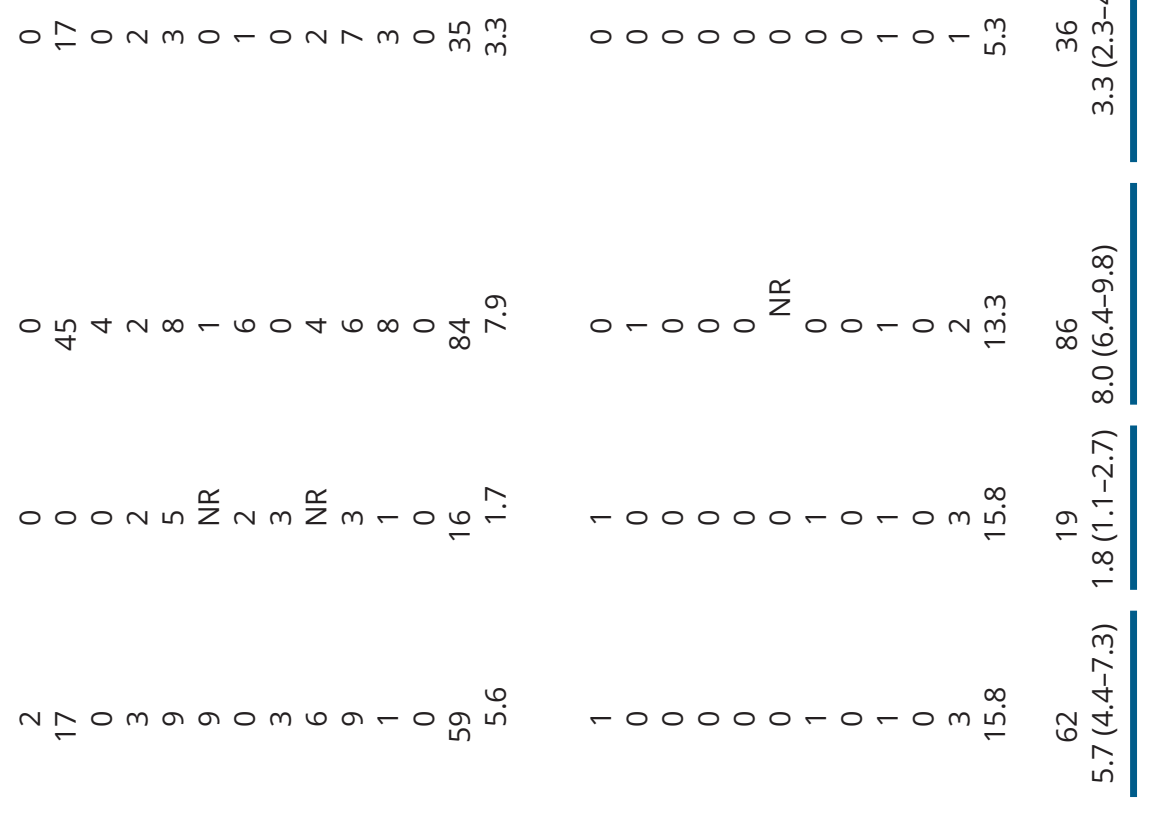

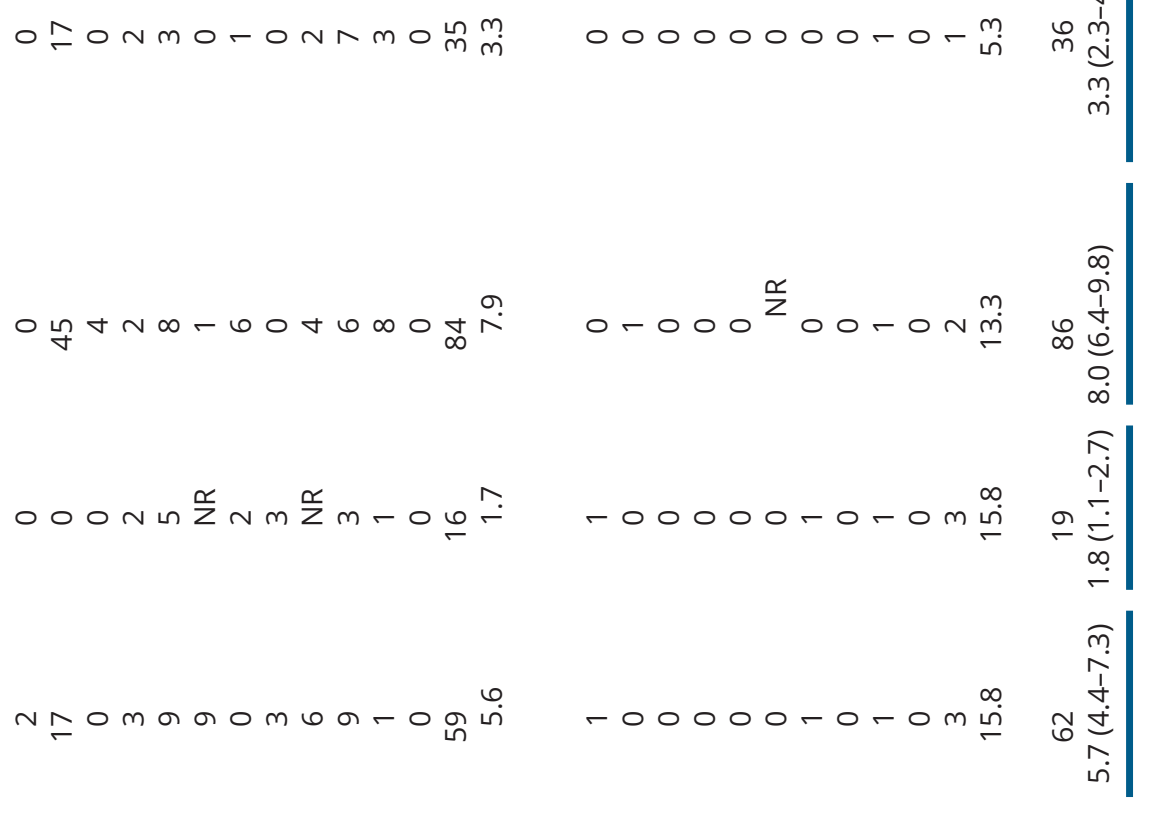

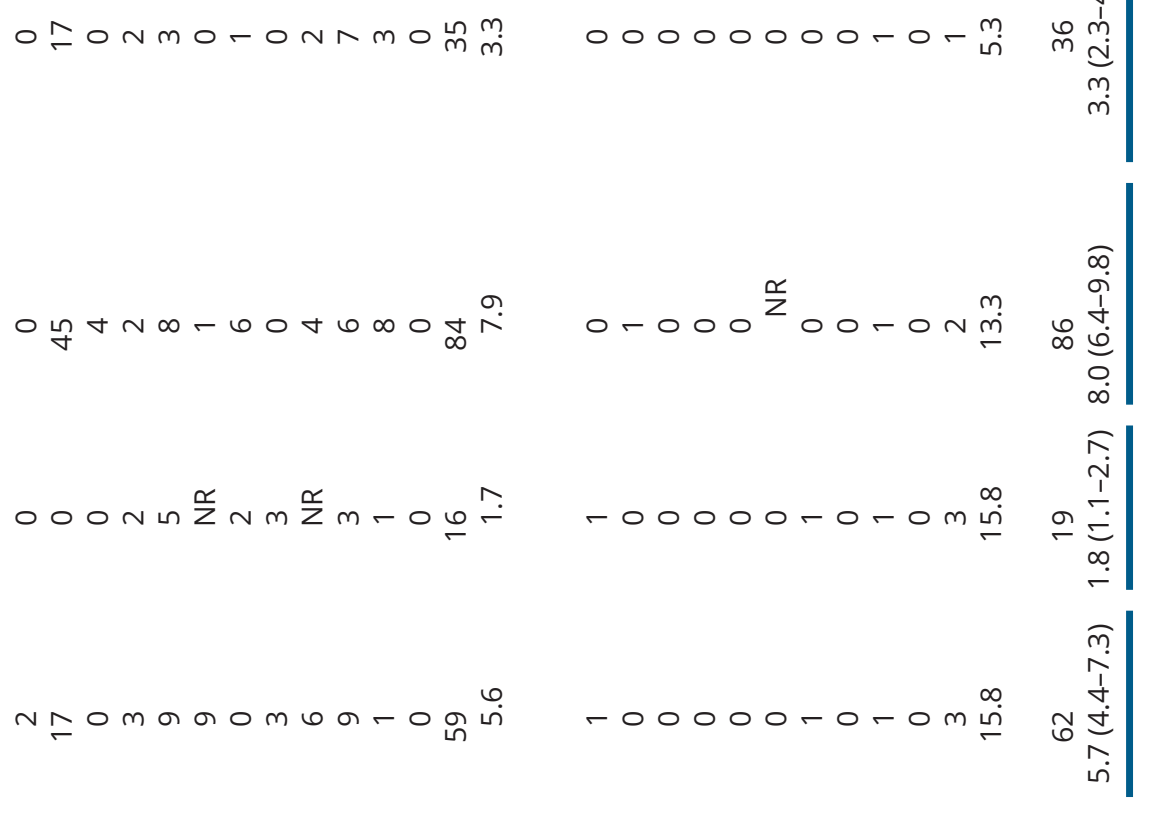

$\underset{m}{\stackrel{m}{m}}$

\begin{tabular}{c}
0 \\
1 \\
\multirow{1}{0}{} \\
0 \\
0 \\
0 \\
$\infty$
\end{tabular}

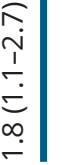

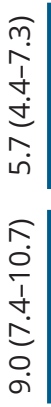

$\stackrel{\infty}{\stackrel{\infty}{\circ}}$

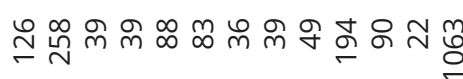

$r-m \in t r-r$

$-+\rightarrow b-+n---\pi$

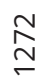

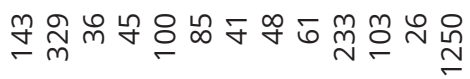$$
r
$$ 
reported (246). Thus, quinagolide appears to be less safe during pregnancy, although the available data are limited.

R.5.4. We recommend stopping the dopamine agonist once pregnancy is established. However, dopamine agonists may be given for a longer gestational period in specific circumstances $(\oplus \bigcirc \bigcirc)$ ).

\section{Rationale}

DA cross the placental barrier and, although the use of bromocriptine and cabergoline has not been associated with increased teratogenicity (see Section 4.1), it is recommended to discontinue treatment as soon as pregnancy is confirmed $(25,232,233)$.

For women with a macroprolactinoma close to the optic chiasm, it should be confirmed that tumour volume has shrunk substantially prior to conception (25). After shrinkage, it is generally safe to discontinue DA. If adenoma size is not controlled, several options are available. First, DA therapy seems to be safe and, in special circumstances, can be continued throughout the pregnancy, particularly if the adenoma is abutting the optic chiasm. Second, DA can be started later in pregnancy in case of symptomatic tumour growth (see R.5.8.). Cabergoline is slightly preferable due to its better tolerability, higher efficacy and longer duration of action. Alternatively, partial or complete resection by transsphenoidal surgery prior to conception can be considered, in particular for cystic lesions that are often considered less responsive to medical therapy and good candidates for surgery. However, one study showed that a large proportion of cystic tumours can also be reduced by DA (247).

Limited safety data are available regarding the use of bromocriptine throughout gestation in mothers with hyperprolactinaemia ( $n=36$ pregnancies and $n=36$ live infants) with no abnormalities noted in the infants except for one balanced translocation of chromosomes 8 and 12 (50), and one case of testicular ectopy, which corrected spontaneously after 7 months (57). The record is even smaller for cabergoline used throughout gestation ( $n=34$ pregnancies and $n=26$ live infants), with no recorded malformations in live infants. There was one foetal death at week 34 in a mother suffering from severe pre-eclampsia (34). A report on 25 pregnancies from India with cabergoline therapy throughout pregnancy showed 1 foetal death, 3 missed abortions, 3 pregnancy terminations due to major congenital malformations, 2 premature deliveries and 18 live infants (64).
R.5.5. We recommend not measuring prolactin during pregnancy.

\section{Rationale}

Pregnancy is associated with a physiological elevation of prolactin concentrations $(248,249)$ and serum prolactin levels may increase about 10-fold throughout pregnancy, reaching levels of $150-300 \mu \mathrm{g} / \mathrm{L}$ at term $(250,251,252)$. A similar prolactin secretory pattern is usually seen in pregnant women with a prolactinoma, often with a greater amplitude (25). However, in some prolactinoma patients, serum prolactin levels may not increase further during pregnancy and prolactin is therefore not a reliable marker of eventual tumour progression $(25,253)$. Therefore, we do not recommend prolactin measurements during gestation in prolactinoma patients. Furthermore, serum prolactin concentrations do not reliably predict the likelihood of normal breastfeeding (254).

R.5.6. We suggest that for women with a small intrasellar microprolactinoma, and normal pituitary function prepregnancy, there is no need for routine endocrinological follow-up during pregnancy.

\section{Rationale}

Data are few regarding the development of pituitary deficiencies during pregnancy in women with prolactinomas. In a study, including 83 patients with prolactinoma, two patients developed TSH deficiency and one developed ACTH deficiency during pregnancy. All three had a macroadenoma and tumour growth was observed in two of them (55). Thus, in women with a microprolactinoma routine endocrine care is not mandatory and endocrinologists should be consulted only in case of symptoms or signs suggesting tumour growth or new-onset hypopituitarism.

R.5.7. We suggest careful and regular monitoring for tumour growth in pregnant women with a large macroprolactinoma or a prolactinoma close to the optic chiasm $(\oplus \oplus \bigcirc \bigcirc)$.

\section{Rationale}

Overall, symptomatic tumour growth during pregnancy occurs in $9.0 \%$ (95\% CI: $6.8-11.6 \%$ ) of prolactinomas. However, in women with a macroprolactinoma, the risk is reported to be considerably higher, 30.5\% (95\% CI: $22.4-$ 
39.7\%), see Section 4.4. A much smaller risk - between 1 and $4 \%$ - was observed in cases where the tumour had been operated, irradiated or sufficiently reduced by prolonged DA therapy before pregnancy $(25,36,51,76,165)$. Data on 85 viable pregnancies in 46 patients with a macroprolactinoma demonstrated tumour growth-related symptoms 12 times in 9 patients (19.6\%) including 3 cases of apoplexy (255).

Therefore, we recommend careful individualised follow-up with clinical evaluation, including visual field testing, visual acuity, OCT and in case of visual deterioration MRI assessment without gadolinium in pregnant women with a macroadenoma which could not be sufficiently reduced by prior treatment.

R.5.8. We recommend to consider restarting dopamine agonists in pregnancy in case of symptoms of progressive prolactinoma growth. Surgery should be used only in case of medical failure or symptomatic apoplexy $(\oplus \bigcirc \bigcirc)$ ).

\section{Rationale}

In case of symptomatic prolactinoma growth during pregnancy, restarting DA is effective in most cases and is therefore first choice $(55,76,78,80,162)$. Cabergoline is slightly preferable in terms of side effects and efficacy, the doses in pregnant women are similar to those in nonpregnant women and the lowest possible dose should be used.

Transsphenoidal surgery is indicated if medical treatment fails to rapidly induce sufficient tumour shrinkage and symptom relief. Rapid decompressive surgery is also indicated in many cases of progressively symptomatic pituitary apoplexy $(181,223)$, which may cause severe visual defects. In case of sudden and severe headache, ophthalmoplegia or limited visual field impairment, surgery should be discussed case-by-case (255). It may occur both in patients treated with DA (64) and in untreated pregnant women with a prolactinoma (247). However, haemorrhagic necrosis of a macroprolactinoma during pregnancy may also be minor or asymptomatic, thus not requiring surgery and having a favourable outcome without treatment (230).

R.5.9. For women with a prolactinoma, breastfeeding is usually feasible and not contraindicated, but we recommend to take into account individual circumstances like tumour size and symptoms.

\section{Rationale}

Lactation is considered safe and feasible. It is also considered safe to withhold DA treatment as long as breastfeeding is desired $(81,230)$. In individual cases of macroadenoma requiring DA throughout pregnancy, the advice to breastfeed and stop DA should be individualised (256). Breastfeeding while taking a DA is not possible and should be avoided anyway.

R.5.10. We recommend reassessing prolactinoma status after every pregnancy before considering restarting therapy.

\section{Rationale}

There is a subset of prolactinomas that will involute during pregnancy and lactation. In various studies, these percentages range from 17 to $68 \%$, on average $40 \%$ for a median time of 22 months (46). There is a higher number of remission in microprolactinomas (46\%) than macroprolactinomas (26\%). Biochemical remission may coincide with tumour disappearance, but small remnant tissue may also persist $(46,230)$. We, therefore, recommend re-evaluating the status of the prolactinoma 1-3 months after the lactation period, with clinical assessment, prolactin measurement, and MRI in cases of previous macroadenomas. In case of remission, we recommend clinical and hormonal follow-up at 6 months and yearly thereafter, since recurrence may occur in up to $65 \%$ of cases.

\subsection{Acromegaly}

Acromegaly may be associated with infertility, through several mechanisms (257), including hypopituitarism and hyperprolactinaemia related to a mixed GH-PRLsecreting adenoma or to pituitary stalk compression. Moreover, excess GH/IGF-I secretion may have a direct effect on hypothalamic gonadotropin-releasing hormone $(\mathrm{GnRH})$ secretion or induce polycystic ovary disease-like conditions.

R.6.1. In women with acromegaly considering pregnancy, we recommend assessment of disease activity, comorbidities and fertility status.

\section{Rationale}

Impaired glucose tolerance, diabetes mellitus and hypertension associated with active acromegaly (258) may worsen in pregnancy and thereby harm the foetus (110, $116,124,147)$. Therefore, control of acromegaly and its complications is recommended in women with acromegaly who wish to conceive. Glucose tolerance and blood pressure should be monitored during pregnancy. Tumour mass effect may also be a concern during pregnancy 
and needs to be carefully evaluated before pregnancy to determine appropriate treatment (see Table 3).

R.6.2. In women with newly diagnosed acromegaly seeking pregnancy, surgery is recommended as first-line therapy.

\section{Rationale}

Surgery is first-line treatment in newly diagnosed women with acromegaly seeking pregnancy (259). If complete removal of the tumour is not feasible, debulking surgery is frequently indicated, especially if the tumour abuts the optic chiasm and impairs visual function (even if the risk of growth during pregnancy is very low) (260). Decision making and intervention should take place in expert pituitary centres, including Pituitary Tumor Centers of Excellence/Endo-ERN Reference Centers .

R.6.3. In women with mild acromegaly, no comorbid conditions and regular ovulatory cycles, pregnancy is considered safe and medical or surgical treatment can be postponed until after delivery.

\section{Rationale}

In patients with mildly elevated IGF-I levels, either newly diagnosed or after surgical treatment, maternal IGF-I levels usually decrease during pregnancy as the high oestrogen levels induce hepatic resistance to GH (110, 116, 119, $124)$ and some patients may experience symptom relief during the first half of pregnancy (260). This, along with the very low risk of symptomatic tumour growth $(7.0 \%$, 95\% CI: 3.3-12.9\%, see Section 4.4), allows postponement or withdrawal of medical or surgical treatment until after delivery unless the mass lesion demands treatment (260). On the other hand, in case of infertility, even if cycles are regular and PRL levels are normal, treatment of acromegaly may be useful to restore fertility (257).

R.6.4. We suggest that for women with acromegaly seeking pregnancy and who have an indication for medical treatment, somatostatin analogues or cabergoline can be used until confirmation of pregnancy if surgery is not an option. Pegvisomant should be reserved for selected uncontrolled cases $(\oplus \circ \bigcirc)$ ).

\section{Rationale}

If complete surgical removal of the adenoma is unfeasible (261), primary medical therapy may be considered even though no drug is approved by either EMA or FDA for the treatment of acromegaly during pregnancy. The potential risks of using these drugs must be weighed against their benefit for fertility and disease control. For more information, see links to summaries of product characteristics (SPCs) and FDA and EMA categorisation (Appendix 6).

In the available literature, there is no clear indication that treatment with cabergoline, octreotide or lanreotide during pregnancy increases adverse events for mother or child. Specifically, treatment with cabergoline and firstgeneration somatostatin analogues does not result in increased prevalence of congenital malformations (see Section 4.2) (260). In $71 \%$ of the patients, first-generation somatostatin analogue treatment was stopped before the end of the first trimester; a smaller number of patients continued treatment throughout pregnancy. Pregnancy was usually uneventful, and most women delivered healthy babies of appropriate height and weight at term, apart from one case of a large newborn (260). Lastly, no excess teratogenic risk of octreotide and lanreotide was reported, but the number of exposed pregnancies was too low to allow firm conclusion about the safety of these drugs. Despite their different category classification by FDA (see links in Appendix 6), there is no evidence for preferring octreotide to lanreotide. There are insufficient data about pasireotide use in pregnancy to make any recommendation about this second generation somatostatin receptor ligand. The Endocrine Society guideline suggests withdrawal of depot somatostatin analogue 2 months prior to conception and to switch to short-acting octreotide (261). With the reassuring safety data reported in this guideline, continuation of depot first-generation somatostatin analogues up to confirmation of pregnancy may, however, be acceptable and preferred by patients.

The experience with pegvisomant is limited. Data on 35 pregnancies (27 involving maternal and 8 paternal pegvisomant exposures) in which pegvisomant treatment of the mother was interrupted as soon as the pregnancy was diagnosed do not suggest adverse consequences of pegvisomant on pregnancy outcome (146). Data are, however, too limited to recommend this treatment during pregnancy unless no other therapy controls severe symptoms of acromegaly.

R.6.5. We recommend to consider stopping drugs for acromegaly once pregnancy is established $(\oplus \bigcirc \bigcirc)$ ).

\section{Rationale}

There is no indication based on available literature that treatment with cabergoline, octreotide or lanreotide during pregnancy results in more congenital 
malformations $(1.3 \%)$ than in the general population (2.4\% in Europe) (105), see Section 4.2. However, as clinical data on the safety of octreotide, lanreotide or pegvisomant are limited, women of childbearing age who receive these drugs should discontinue the treatment when pregnancy is confirmed as a safety precaution. Since the high oestrogen levels during pregnancy induce GH resistance, acromegaly symptoms tend to improve, and stopping drugs is generally regarded as safe. Only severe headache, serious endocrine symptoms or tumour volume issues may require reinstitution of drugs. In the infrequent cases when this is needed, we suggest to start dose titration with short-acting sc octreotide aiming at the lowest possible effective dose.

R.6.6. We recommend not to measure GH and IGF-I during pregnancy.

\section{Rationale}

During normal pregnancy, the placenta produces a GH variant (hPGH) (262), which cross-reacts with pituitary GH in most immunoassays (263). During the first trimester of normal pregnancy, maternal IGF-I levels decrease by about 30\% (264) and thereafter may increase to reach a peak at 37 weeks of gestation that is two-fold elevated as compared to the pre-pregnancy level (265); in some cases, this peak is not observed $(110,116,119,124)$. Taken together, measurements of serum GH and IGF-I levels do not provide useful clinical information and are therefore not recommended (261).

R.6.7. We suggest that for pregnant women with large adenomas, or adenomas close to the optic chiasm, regular neuro-ophthalmologic and, if necessary, pituitary MRI examination be performed.

\section{Rationale}

During normal pregnancy, the pituitary size may increase by up to $45 \%$ during the first trimester, which may predispose to compressive symptoms (222). It is unclear if pregnancy may trigger the growth of a pre-existing GH-secreting pituitary adenoma, but discontinuation of somatostatin analogue treatment may allow regrowth of the tumour $(113,126)$. Overall, symptomatic tumour growth during pregnancy in acromegaly is seen in $7.0 \%$ of patients (95\% CI: $3.3-12.9 \%$ ), see Section 4.4 .
Development of visual field defects during pregnancy is rare $(124,222,260)$, whereas headache is more frequent $(110,116,124)$. Surveillance with neuroophthalmological evaluation and - in case of visual impairment - MRI without contrast is indicated.

R.6.8. We suggest to consider starting or restarting medical treatment for tumour control and severe clinical symptoms attributable to acromegaly $(\oplus \bigcirc \bigcirc)$ ).

\section{Rationale}

Medical treatment with octreotide or lanreotide is suggested as first-line treatment in the event of symptomatic tumour enlargement with visual loss or neurological complications, even though surgery in the second trimester, in general, is considered safe (223). Medical treatment with DA has also been used but is probably less effective $(110,117,118$, $122,124,143,150,266)$. The duration of the treatment depends on the severity of symptoms and some patients have been treated throughout with dopamine agonists or first-generation somatostatin analogues (260). Treatment of hyperglycaemia and hypertension should follow general guidelines for pregnant women (110, 116, 147).

R.6.9. In acromegaly, breastfeeding is feasible and not contraindicated, but we recommend to take individual circumstances like drug use and disease activity into account.

\section{Rationale}

Breastfeeding is generally possible and not contraindicated $(106,110,111,112,113,116,139)$. As a safety principle, somatostatin analogues and pegvisomant should be avoided in nursing mothers (see section 5.3).

R.6.10. We recommend reassessing disease activity after pregnancy.

\section{Rationale}

Shortly after delivery, a rebound of disease activity is frequently observed $(110,116,124,126,139,267)$; therefore, early resumption of treatment may be indicated. A postpartum MRI should be performed in most patients with a previously documented adenoma, timing depending on disease severity, and known remnant. Gadolinium should not be used if the mother is breastfeeding. 


\subsection{Cushing's disease}

Although this Guideline is focused on pituitary tumours and pregnancy, it is important to note that published data often include adrenal as well as pituitary cases of Cushing's syndrome (CS), and that hypercortisolism from any source may have a significant negative impact on the mother and foetus. Hypercortisolism leads to hypogonadism and infertility; thus, pregnancy in $\mathrm{CD}$ is very rare. When women with CS do become pregnant, it is most often of adrenal origin (60\% of cases) (26). This is in contrast to non-pregnant women, where $\mathrm{CD}$ is responsible for $70 \%$ of the cases.

R.7.1. We recommend that women with active Cushing's syndrome be advised not to get pregnant.

\section{Rationale}

Pregnancy should be avoided in the presence of Cushing's syndrome of any aetiology, given the increased incidence of both maternal and foetal complications $(18,26,268)$. Women with active CS show a high incidence of pre-term deliveries, probably due to more frequent complications during pregnancy such as gestational diabetes mellitus, hypertension or pre-eclampsia; additionally, a higher rate of Caesarean section in comparison to cured CS is reported (51.7\% vs $21.9 \%$ ) (26). Foetal risks are also higher, and include deaths, pre-term births, neonatal infections, hypoglycaemia, and respiratory distress. Foetal loss is higher in non-treated mothers (30.6\% of cases), but also increased in women treated during pregnancy, either medically (20.8\%) or surgically (12.5\%). Other major foetal morbidities are pre-term delivery $(66.3 \%$ in untreated patients, $76.2 \%$ if treated medically, $56.1 \%$ if treated surgically during pregnancy) and low birth weight (68.3, 68.8 and $73.3 \%$, respectively) (18).

When foetal loss and global foetal morbidity are compared between active and cured CS, both are much higher in active disease (23.6 vs $8.5 \%$ and 33.3 vs $4.9 \%$, respectively). In cured CS, both maternal and foetal risks tend to normalise. Prior obstetric complications are much more frequent than in the general population; since diagnostic delay in CS is very common in nonpregnant women, this suggests there is a negative effect of undiagnosed hypercortisolism long before the diagnosis of CS.

R.7.2. Evaluation of hypercortisolism during pregnancy is difficult; we suggest to consider testing only for high clinical suspicion of new diagnosis of Cushing's disease.

\section{Rationale}

Making a new diagnosis of CS during pregnancy can be challenging because some of the clinical features overlap those occurring in normal pregnancy, including hyperglycaemia, central weight gain, hypertension, fatigue, skin pigmentation, facial plethora and the development of striae. Clinical features which are not typical of normal pregnancy include striae on sites other than the abdomen and striae that are wider and more purple than usual for pregnancy, easy bruising, skin thinning, spontaneous fractures and proximal myopathy. However, biochemical confirmation is needed, and this can be challenging. The HPA axis is activated during normal pregnancy, producing increased levels of CRH (much of it originating from the placenta), ACTH and serum total and free cortisol (211). There is also increased hepatic production of cortisol binding globulin related to high levels of oestrogen, which further increases measured serum cortisol (211). Urinefree cortisol (UFC) excretion increases up to three-fold during pregnancy and overlaps with CS levels (269). Therefore, UFC values above this threshold are needed to be confident of the diagnosis. Suppression of cortisol by dexamethasone is blunted in pregnancy, so the $1 \mathrm{mg}$ overnight dexamethasone suppression test is not advised due to the risk of false-positive results (269); up to $60 \%$ of normal pregnant women may fail to suppress below $50 \mathrm{nmol} / \mathrm{L}(1.8 \mu \mathrm{g} / \mathrm{dL})(211)$. Because cortisol circadian rhythm is maintained in normal pregnancy (although at a higher level of cortisol), late night salivary cortisol or midnight serum cortisol levels have been suggested as possible diagnostic tests. Late night salivary cortisol levels also increase during pregnancy, but it has been reported that it may prove to be a valuable tool to diagnose CS in pregnancy with sensitivities of $>80 \%$ and specificities of $>93 \%$ using an ELISA-Cortisol EIA kit (salimetrics) and the following cutoffs: $0.255 \mu \mathrm{g} / \mathrm{dL}(7.0 \mathrm{nmol} / \mathrm{L})$ for the first trimester, $0.260 \mu \mathrm{g} / \mathrm{dL}(7.2 \mathrm{nmol} / \mathrm{L})$ for the second trimester, and $0.285 \mu \mathrm{g} / \mathrm{dL}(7.9 \mathrm{nmol} / \mathrm{L})$ for the third trimester (270). If confirmed with other assays, this may become the diagnostic test of choice when CS is suspected in a pregnant woman.

When the diagnosis of CS has been established, biochemical testing to determine the location is also challenging; insufficient data are available for high dose dexamethasone and $\mathrm{CRH}$ testing to make a recommendation (271). If a pituitary source is suspected based on high normal to elevated ACTH, pituitary MRI can be performed without gadolinium, although many corticotroph adenomas are 
small and may be missed. MRI with gadolinium could be performed during pregnancy given that no obvious adverse events have been reported, but the balance between the benefit and the potential risk should be carefully discussed. Bilateral inferior petrosal sinus sampling is not advised during pregnancy due to the radiation involved and the increased potential for venous thrombosis (272). When adrenal CS is suspected based on suppressed or low normal ACTH, ultrasound imaging of the adrenals may be performed but abdominal MRI without contrast seems best to characterise the adrenal mass.

R.7.3. We recommend that in women with Cushing's disease, medically treated and considering pregnancy, pros and cons of different therapeutic options to reduce cortisol concentrations should be carefully considered $(\oplus \circ \bigcirc))$.

\section{Rationale}

Treatment during pregnancy has been reported in less than 100 cases of endogenous CS of any origin, either surgery (24\%), medical treatment (11\%) or both (4.7\%) (26). Only ten cases of Cushing's disease with medical treatment during pregnancy were found in the literature (see Section 4.3). Drugs most often reported were cabergoline, ketoconazole and metyrapone. However, none is approved for use in pregnancy. Adverse event rates were high for both mother (60\%, 95\% CI: $26-88 \%)$ and infant (58\%, 95\% CI: $28-85 \%)$, although no congenital malformations were reported. There are insufficient data about pasireotide and osilodrostat use in pregnancy; due to their side effects, they should be avoided.

The limited number of cases described precludes any definite conclusion as to the best management for CS during pregnancy; it depends on the cause, the stage of pregnancy and the severity of hypercortisolism. However, untreated CS is associated with more maternal and foetal morbidity. While medical or surgical treatment decreased the risk of perinatal mortality and maternal morbidity, it did not protect from prematurity or intrauterine growth restriction $(18,26,272)$.

If treatment is considered necessary, surgery in the second trimester has been recommended as a first-choice treatment, but the evidence is limited (see Section 4.5). No specific congenital malformations appear to be more frequent in babies delivered from CS patients (26).

R.7.4. We recommend that pregnant women with active or medically treated Cushing's disease should be managed by a multidisciplinary team expert in high-risk pregnancies.

\section{Rationale}

The multidisciplinary team should include obstetricians, pituitary specialists, neonatologists, and specialised endocrine surgeons. Mild cases of CS, especially those discovered late in pregnancy, may be treated conservatively by controlling comorbidities. In women who become pregnant while on anti-cortisolic treatment (exception cabergoline), there should be a discussion about the fact that little is known about possible teratogenic effects as well as maternal risk and pregnancy termination.

In women who develop severe CD while pregnant, the first option to consider is surgery (pituitary adenomectomy or laparoscopic adrenalectomy) (273). In a systematic review of pregnancies in women diagnosed with CS, 61 underwent surgery at a gestational age of 21 (range 17-26) weeks. Among these, 11 were transsphenoidal pituitary surgeries, 44 unilateral adrenalectomies and 6 bilateral adrenalectomies. Seventy-seven per cent attained remission, $12 \%$ were still active and in $10 \%$ information was not available. Foetal loss (6.7\% vs $28.6 \%)$, pre-term birth $(56.1 \%$ vs $80 \%)$, and low birth weight (70.6\% vs $100 \%)$ were lower if remission was attained after surgery compared to those not in remission (26).

Medical therapy can be contemplated when surgery is contraindicated, or initially after diagnosis for symptomatic control. Metyrapone has been most commonly used; as it may worsen hypertension and/or decrease potassium, blood pressure and potassium should be regularly monitored. Ketoconazole is another option for treatment, although fewer outcome data are available. Cabergoline has only been reported in three cases of CD with good maternal-foetal outcome, but breast feeding would not be possible. No reports of pasireotide or osilodrostat use during pregnancy in CS are available. Mifepristone, a glucocorticoid receptor blocker available in some countries, is contraindicated as it is also a progesterone blocker used to terminate a pregnancy.

The possibility of premature delivery should be anticipated in $\mathrm{CD}$, and consideration given to induced early delivery, if indicated. When control is not possible, with life-threatening risks for the mother and the foetus, pregnancy termination for medical reasons should be discussed.

R.7.5. We suggest to consider treating pregnant women with active Cushing's disease with prophylactic anticoagulation (low molecular weight heparin). 


\section{Rationale}

CS increases the risk of thrombotic events up to 10-fold, which has been attributed to an increase in plasma clotting factors and impaired fibrinolysis (274, 275, 276, 277). A recent cohort study of 208 patients with CS $(89.4 \%$ of pituitary origin) showed an overall thrombotic rate of 18\% (276). Anti-thrombotic prophylaxis has been shown to reduce morbidity and mortality in Cushing's syndrome $(275,277)$. Separate from this, the risk of thrombosis is also increased in pregnancy. Therefore, the risk might be even higher in pregnant women with CS. However, there are currently no data addressing the question of whether thromboprophylaxis would be beneficial and safe in pregnant women with CS. Given the clearly increased thrombosis risk, the panel concluded it is reasonable to consider prophylactic treatment with low molecular weight heparin.

R.7.6. We recommend to reassess disease activity after pregnancy.

\section{Rationale}

A reassessment of cortisol excess should be conducted after delivery in women with Cushing's disease. In a woman without CS, the pregnancy-related HPA axis activation subsides within days after delivery and is typically back to non-pregnant levels within a few weeks $(272,278)$. Restoration of normal dexamethasone suppressibility of cortisol, however, may take over a month after delivery (211) and CBG elevations may be seen up to 3 months post-partum (278). Therefore, reassessment of disease state after delivery in a woman with CD is generally advised 2-3 months post-partum.

R.7.7. We recommend that breastfeeding be considered.

\section{Rationale}

Breastfeeding is not contraindicated if the mother's general condition allows it, and she is not taking steroid synthesis inhibiting drugs, pasireotide or cabergoline.

\section{Suggestions for future research}

Many questions still remain about theoptimal management of pituitary tumours in pregnant women. We suggest that future research include the following questions:

- Is transsphenoidal surgery for pituitary adenomas safe during pregnancy?
- If surgery is needed for pregnant women with pituitary tumours, is there an optimal timing or can it be done during any trimester?

- Are pasireotide and pegvisomant safe and effective in pregnant women with acromegaly?

- Can the utility of trimester-based cutoffs for late-night salivary cortisol in pregnancy be confirmed?

- Are there any novel methods that would establish the diagnosis of Cushing's disease in pregnancy, given the activation of the hypothalamic-pituitary-adrenal axis in normal pregnancy?

- Does therapy with low molecular weight heparin (LMWH) reduce the risk of thromboembolic events in pregnant women with Cushing's disease?

- Is LMWH safe for pregnant women and the foetus when used in Cushing's disease?

- What are the benefits and risks of medical treatment in pregnant women with Cushing's disease, particularly the new drugs including pasireotide and osilodrostat?

\section{Supplementary materials}

This is linked to the online version of the paper at https://doi.org/10.1530/ EJE-21-0462.

\section{Declaration of interest}

B M K Biller: receipt of consultation fees from Ascendis, Aeterna Zentaris, Chiasma, Diurnal, Merck Serono, Novo Nordisk, Ono, Pfizer, Recordati, Strongbridge, Tiburio and grants or research support to Massachusetts General Hospital from Crinetics, lonis, Novo Nordisk, Novartis; P Chanson: receipt of honoraria and/or consultation fees from Ipsen, Novartis, Pfizer and grants or research support from Ipsen, Novartis, Pfizer; J O L Jorgensen: receipt of honoraria and/or consultation fees from Ascendis, Ipsen, Novartis, Novo Nordisk, Pfizer and grants or research support from Novartis, Pfizer; A Luger: receipt of honoraria and/or consultation fees from Ipsen, Merck Serono, Novartis, Pfizer, Sandoz and grants or research support from Ipsen, Novartis, Pfizer; S Llahana: receipt of honoraria from Ipsen, Pfizer; R Verkauskiene: receipt of honoraria and/or consultation fees from Novartis, Pfizer, Sandoz; S Webb: receipt of honoraria and/or consultation fees from Corcept, Crinetics, HRA, Ipsen, Pfizer, Recordati and grants or research support from HRA. The other authors declare no conflict of interest.

\section{Funding}

This work did not receive any specific grant from any funding agency in the public, commercial, or not-for-profit sector.

\section{Acknowledgements}

The authors thank Prof Felipe Casanueva, Santiago de Compostela, Spain, Prof Sophie Christin-Maitre, Paris, France, Prof Thomas Graillon, Marseille, France, and Prof Marija Pfeifer, Ljubljana, Slovenia for kindly providing suggestions about the manuscript before journal submission. The manuscript was then sent to all members of the ESE as well as to 
the Endocrine Society, the European Neuroendocrine Association, the European Association of Neurosurgical Societies, the European Reference Network on Rare Endocrine Conditions (Endo-ERN). Comments received and responses to comments are listed in the supplementary materials, Appendix 7.

\section{References}

1 Gonzalez JG, Elizondo G, Saldivar D, Nanez H, Todd LE \& Villarreal JZ. Pituitary gland growth during normal pregnancy: an in vivo study using magnetic resonance imaging. American Journal of Medicine 1988 85 217-220. (https://doi.org/10.1016/s0002-9343(88)80346-2)

2 Elster AD, Sanders TG, Vines FS \& Chen MY. Size and shape of the pituitary gland during pregnancy and post partum: measurement with MR imaging. Radiology 1991181 531-535. (https://doi.org/10.1148/ radiology.181.2.1924800)

3 Dinc H, Esen F, Demirci A, Sari A \& Resit Gumele H. Pituitary dimensions and volume measurements in pregnancy and post partum. MR assessment. Acta Radiologica 199839 64-69. (https://doi. org/10.1080/02841859809172152)

4 Scheithauer BW, Sano T, Kovacs KT, Young Jr WF, Ryan N \& Randall RV. The pituitary gland in pregnancy: a clinicopathologic and immunohistochemical study of 69 cases. Mayo Clinic Proceedings 1990 65 461-474. (https://doi.org/10.1016/s0025-6196(12)60946-x)

5 Freemark M. Placental hormones and the control of fetal growth. Journal of Clinical Endocrinology and Metabolism 201095 2054-2057. (https://doi.org/10.1210/jc.2010-0517)

6 Costa MA. The endocrine function of human placenta: an overview. Reproductive Biomedicine Online 201632 14-43. (https://doi. org/10.1016/j.rbmo.2015.10.005)

7 Schock H, Zeleniuch-Jacquotte A, Lundin E, Grankvist K, Lakso HÅ, Idahl A, Lehtinen M, Surcel HM \& Fortner RT. Hormone concentrations throughout uncomplicated pregnancies: a longitudinal study. BMC Pregnancy and Childbirth 201616146. (https://doi.org/10.1186/s12884-016-0937-5)

8 Karaca Z, Tanriverdi F, Unluhizarci K \& Kelestimur F. Pregnancy and pituitary disorders. European Journal of Endocrinology 2010162 453-475. (https://doi.org/10.1530/EJE-09-0923)

9 Asvold BO, Eskild A, Jenum PA \& Vatten LJ. Maternal concentrations of insulin-like growth factor I and insulin-like growth factor binding protein 1 during pregnancy and birth weight of offspring. American Journal of Epidemiology 2011 174 129-135. (https://doi.org/10.1093/aje/kwr067)

10 Hershman JM. Physiological and pathological aspects of the effect of human chorionic gonadotropin on the thyroid. Best Practice and Research: Clinical Endocrinology and Metabolism 200418 249-265. (https://doi.org/10.1016/j.beem.2004.03.010)

11 Feldt-Rasmussen U \& Mathiesen ER. Endocrine disorders in pregnancy: physiological and hormonal aspects of pregnancy. Best Practice and Research: Clinical Endocrinology and Metabolism 201125 875-884. (https://doi.org/10.1016/j.beem.2011.07.004)

12 Alexander EK, Pearce EN, Brent GA, Brown RS, Chen H, Dosiou C, Grobman WA, Laurberg P, Lazarus JH, Mandel SJ et al. 2017 Guidelines of the American Thyroid Association for the diagnosis and management of thyroid disease during pregnancy and the postpartum. Thyroid 201727 315-389. (https://doi.org/10.1089/ thy.2016.0457)

13 McNeil AR \& Stanford PE. Reporting thyroid function tests in pregnancy. Clinical Biochemist: Reviews 201536 109-126.

14 Petraglia F, Imperatore A \& Challis JR. Neuroendocrine mechanisms in pregnancy and parturition. Endocrine Reviews 201031 783-816. (https://doi.org/10.1210/er.2009-0019)

15 Petraglia F, Sawchenko PE, Rivier J \& Vale W. Evidence for local stimulation of ACTH secretion by corticotropin-releasing factor in human placenta. Nature 1987328 717-719. (https://doi. org $/ 10.1038 / 328717 \mathrm{a} 0)$
16 Smith R, Smith JI, Shen X, Engel PJ, Bowman ME, McGrath SA, Bisits AM, McElduff P, Giles WB \& Smith DW. Patterns of plasma corticotropin-releasing hormone, progesterone, estradiol, and estriol change and the onset of human labor. Journal of Clinical Endocrinology and Metabolism 200994 2066-2074. (https://doi.org/10.1210/jc.20082257)

17 Challis JRG, Matthews SG, Gibb W \& Lye SJ. Endocrine and paracrine regulation of birth at term and preterm. Endocrine Reviews 200021 514-550. (https://doi.org/10.1210/edrv.21.5.0407)

18 Bronstein MD, Machado MC \& Fragoso MC. Management of endocrine disease: management of pregnant patients with Cushing's syndrome. European Journal of Endocrinology 2015173 R85-R91. (https://doi.org/10.1530/EJE-14-1130)

19 Schrier RW. Systemic arterial vasodilation, vasopressin, and vasopressinase in pregnancy. Journal of the American Society of Nephrology 201021 570-572. (https://doi.org/10.1681/ ASN.2009060653)

20 Casanueva FF, Barkan AL, Buchfelder M, Klibanski A, Laws ER, Loeffler JS, Melmed S, Mortini P, Wass J, Giustina A et al. Criteria for the definition of pituitary tumor centers of excellence (PTCOE): a Pituitary Society Statement. Pituitary 201720 489-498. (https://doi. org/10.1007/s11102-017-0838-2)

21 Bollerslev J, Rejnmark L, Marcocci C, Shoback DM, Sitges-Serra A, van Biesen W, Dekkers OM \& European Society of Endocrinology. European Society of Endocrinology Clinical Guideline: treatment of chronic hypoparathyroidism in adults. European Journal of Endocrinology 2015 173 G1-G20. (https://doi.org/10.1530/EJE-15-0628)

22 Andrews J, Guyatt G, Oxman AD, Alderson P, Dahm P, Falck-Ytter Y, Nasser M, Meerpohl J, Post PN, Kunz R et al. GRADE guidelines: 14. Going from evidence to recommendations: the significance and presentation of recommendations. Journal of Clinical Epidemiology 201366 719-725. (https://doi.org/10.1016/j.jclinepi.2012.03.013)

23 Andrews JC, Schunemann HJ, Oxman AD, Pottie K, Meerpohl JJ, Coello PA, Rind D, Montori VM, Brito JP, Norris S et al. GRADE guidelines: 15. Going from evidence to recommendationdeterminants of a recommendation's direction and strength. Journal of Clinical Epidemiology 201366 726-735. (https://doi.org/10.1016/j. jclinepi.2013.02.003)

24 Guyatt GH, Schunemann HJ, Djulbegovic B \& Akl EA. Guideline panels should not GRADE good practice statements. Journal of Clinical Epidemiology 201568 597-600. (https://doi.org/10.1016/j. jclinepi.2014.12.011)

25 Molitch ME. Endocrinology in pregnancy: management of the pregnant patient with a prolactinoma. European Journal of Endocrinology 2015172 R205-R213. (https://doi.org/10.1530/EJE-14-0848)

26 Caimari F, Valassi E, Garbayo P, Steffensen C, Santos A, Corcoy R \& Webb SM. Cushing's syndrome and pregnancy outcomes: a systematic review of published cases. Endocrine 201755 555-563. (https://doi. org/10.1007/s12020-016-1117-0)

27 Talge NM, Mudd LM, Sikorskii A \& Basso O. United States birth weight reference corrected for implausible gestational age estimates. Pediatrics 2014133 844-853. (https://doi.org/10.1542/peds.20133285)

28 Abid S, Sadiq I, Anwar S, Hafeez M \& Butt F. Pregnancy with macroprolactinoma. Journal of the College of Physicians and Surgeons: Pakistan 200818 787-788. (https://doi.org/12.2008/JCPSP.787788)

29 Almistehi WM \& Almalki MH. Beat the giant: case of a giant prolactinoma during pregnancy on cabergoline. Endocrinology, Diabetes and Metabolism Case Reports 20182018 18-0099. (https://doi. org/10.1530/EDM-18-0099)

30 al-Sharafi BA \& Nassar OH. Successful pregnancy in a female with a large prolactinoma after pituitary tumor apoplexy. Case Reports in Obstetrics and Gynecology 20132013 817603. (https://doi. org $/ 10.1155 / 2013 / 817603)$

31 Araujo B, Belo S \& Carvalho D. Pregnancy and tumor outcomes in women with prolactinoma. Experimental and Clinical 
Endocrinology and Diabetes 2017125 642-648. (https://doi. org/10.1055/s-0043-112861)

32 Bajwa SK, Bajwa SJ, Mohan P \& Singh A. Management of prolactinoma with cabergoline treatment in a pregnant woman during her entire pregnancy. Indian Journal of Endocrinology and Metabolism 201115 (Supplement 3) S267-S270. (https://doi.org/10.4103/2230-8210.84883)

33 Balen AH \& Prentice MG. Gynaecological case reports: spontaneous conception in a woman with Turner mosaicism, polycystic ovaries and hyperprolactinaemia secondary to a pituitary macroadenoma. Journal of Obstetrics and Gynaecology 199414 117-118. (https://doi. org/10.3109/01443619409030027)

34 Banerjee A, Wynne K, Tan T, Hatfield EC, Martin NM, Williamson C $\&$ Meeran K. High dose cabergoline therapy for a resistant macroprolactinoma during pregnancy. Clinical Endocrinology 200970 812-813. (https://doi.org/10.1111/j.1365-2265.2008.03425.x)

35 Belchetz PE, Carty A, Clearkin LG, Davis JC, Jeffreys RV \& Rae PG. Failure of prophylactic surgery to avert massive pituitary expansion in pregnancy. Clinical Endocrinology 198625 325-330. (https://doi. org/10.1111/j.1365-2265.1986.tb01698.x)

36 Bergh T, Nillius SJ \& Wide L. Clinical course and outcome of pregnancies in amenorrhoeic women with hyperprolactinaemia and pituitary tumors. BMJ 19781 875-880. (https://doi.org/10.1136/ bmj.1.6117.875)

37 Bergh T, Nillius SJ, Enoksson P \& Wide L. Bromocriptine-induced regression of a suprasellar extending prolactinoma during pregnancy. Journal of Endocrinological Investigation 19847 133-136. (https://doi. org/10.1007/BF03348403)

38 Campagnoli C, Belforte L, Massara F, Peris C \& Molinatti GM. Partial remission of hyperprolactinemic amenorrhea after bromocriptineinduced pregnancy. Journal of Endocrinological Investigation 19814 85-91. (https://doi.org/10.1007/BF03349421)

39 Canales ES, Garcia IC, Ruiz JE \& Zarate A. Bromocriptine as prophylactic therapy in prolactinoma during pregnancy. Fertility and Sterility 198136 524-526. (https://doi.org/10.1016/s00150282(16)45806-1)

40 Cannavo S, Curto L, Squadrito S, Almoto B, Vieni A \& Trimarchi F. Cabergoline: a first-choice treatment in patients with previously untreated prolactin-secreting pituitary adenoma. Journal of Endocrinological Investigation 199922 354-359. (https://doi. org/10.1007/BF03343573)

41 Colao A, Loche S, Cappa M, di Sarno A, Landi ML, Sarnacchiaro F, Facciolli G \& Lombardi G. Prolactinomas in children and adolescents. Clinical presentation and long-term follow-up. Journal of Clinical Endocrinology and Metabolism 199883 2777-2780. (https://doi. org/10.1210/jcem.83.8.5001)

42 Couture N, Aris-Jilwan N \& Serri O. Apoplexy of a microprolactinoma during pregnancy: case report and review of literature. Endocrine Practice 201218 e147-e150. (https://doi.org/10.4158/EP12106.CR)

43 Crosignani P, Ferrari C \& Mattei AM. Visual field defects and reduced visual acuity during pregnancy in two patients with prolactinoma: rapid regression of symptoms under bromocriptine. Case reports. British Journal of Obstetrics and Gynaecology 198491 821-823. (https:// doi.org/10.1111/j.1471-0528.1984.tb04859.x)

44 de Wit W, Coelingh Bennink HJ \& Gerards LJ. Prophylactic bromocriptine treatment during pregnancy in women with macroprolactinomas: report of 13 pregnancies. British Journal of Obstetrics and Gynaecology 198491 1059-1069. (https://doi. org/10.1111/j.1471-0528.1984.tb15076.x)

45 Dietemann JL, Portha C, Cattin F, Mollet E \& Bonneville JF. CT follow-up of microprolactinomas during bromocriptine-induced pregnancy. Neuroradiology 198325 133-138. (https://doi.org/10.1007/ BF00455732)

46 Domingue ME, Devuyst F, Alexopoulou O, Corvilain B \& Maiter D. Outcome of prolactinoma after pregnancy and lactation: a study on 73 patients. Clinical Endocrinology 201480 642-648. (https://doi. org/10.1111/cen.12370)
47 Dommerholt HB, Assies J \& van der Werf AJ. Growth of a prolactinoma during pregnancy. Case report and review. British Journal of Obstetrics and Gynaecology 198188 62-70. (https://doi. org/10.1111/j.1471-0528.1981.tb00939.x)

48 Faglia G, Conti A, Muratori M, Togni E, Travaglini P, Zanotti A \& Mailland F. Dihydroergocriptine in management of microprolactinomas. Journal of Clinical Endocrinology and Metabolism 198765 779-784. (https://doi.org/10.1210/jcem-65-4-779)

49 Gondim J, Ramos Junior F, Pinheiro I, Schops M \& Tella Junior OI. Minimally invasive pituitary surgery in a hemorrhagic necrosis of adenoma during pregnancy. Minimally Invasive Neurosurgery 200346 173-176. (https://doi.org/10.1055/s-2003-40734)

50 Goodman LA \& Chang RJ. Pregnancy after bromocriptineinduced reduction of an extrasellar prolactin-secreting pituitary macroadenoma. Obstetrics and Gynecology 198464 (3 Supplement) 2S-7S. (https://doi.org/10.1097/00006250-198409001-00001)

51 Grossman A, Cohen BL, Charlesworth M, Plowman PN, Rees LH, Wass JA, Jones AE \& Besser GM. Treatment of prolactinomas with megavoltage radiotherapy. BMJ 1984288 1105-1109. (https://doi. org/10.1136/bmj.288.6424.1105)

52 Hammond CB, Haney AF, Land MR, van der Merwe JV, Ory SJ \& Wiebe RH. The outcome of pregnancy in patients with treated and untreated prolactin-secreting pituitary tumors. American Journal of Obstetrics and Gynecology 1983147 148-157. (https://doi. org/10.1016/0002-9378(83)90108-4)

53 Hoffmann G, Ackermann RH, Happ J, Hey O \& Pollow K. Pregnancy and hyperprolactinemia. Experimental and Clinical Endocrinology 1983 81 336-346. (https://doi.org/10.1055/s-0029-1210245)

54 Jewelewicz R \& Vande Wiele RL. Clinical course and outcome of pregnancy in twenty-five patients with pituitary microadenomas. American Journal of Obstetrics and Gynecology 1980136 339-343. (https://doi.org/10.1016/0002-9378(80)90859-5)

55 Karaca Z, Yarman S, Ozbas I, Kadioglu P, Akturk M, Kilicli F, Dokmetas HS, Colak R, Atmaca H, Canturk Z et al. How does pregnancy affect the patients with pituitary adenomas: a study on 113 pregnancies from Turkey. Journal of Endocrinological Investigation 2018 41 129-141. (https://doi.org/10.1007/s40618-017-0709-8)

56 Koizumi K \& Aono T. Pregnancy after combined treatment with bromocriptine and tamoxifen in two patients with pituitary prolactinomas. Fertility and Sterility 198646 312-314. (https://doi. org/10.1016/s0015-0282(16)49531-2)

57 Konopka P, Raymond JP, Merceron RE \& Seneze J. Continuous administration of bromocriptine in the prevention of neurological complications in pregnant women with prolactinomas. American Journal of Obstetrics and Gynecology 1983146 935-938. (https://doi. org/10.1016/0002-9378(83)90968-7)

58 Liu C \& Tyrrell JB. Successful treatment of a large macroprolactinoma with cabergoline during pregnancy. Pituitary 20014 179-185. (https:// doi.org/10.1023/a:1015319007880)

59 Liu X, Liu Y, Gao J, Feng M, Bao X, Deng K, Yao Y \& Wang R. Combination treatment with bromocriptine and metformin in patients with bromocriptine-resistant prolactinomas: pilot study. World Neurosurgery 2018115 94-98. (https://doi.org/10.1016/j. wneu.2018.02.188)

60 Mitsiakos G \& Gkampeta A. A possible role of GDNF expression by which cabergoline use affects corpus callosum. Journal of Pediatric and Neonatal Individualized Medicine 20198 e080112. (https://doi.org/10.7363/080112)

61 Modena G \& Portioli I. Delivery after bromocriptine therapy. Lancet 19772 558. (https://doi.org/10.1016/s0140-6736(77)90690-0)

62 Morange I, Barlier A, Pellegrini I, Brue T, Enjalbert A \& Jaquet P. Prolactinomas resistant to bromocriptine: long-term efficacy of quinagolide and outcome of pregnancy. European Journal of Endocrinology 1996135 413-420. (https://doi.org/10.1530/ eje.0.1350413)

63 Ono M, Miki N, Amano K, Kawamata T, Seki T, Makino R, Takano K, Izumi S, Okada Y \& Hori T. Individualized high-dose cabergoline 
therapy for hyperprolactinemic infertility in women with micro- and macroprolactinomas. Journal of Clinical Endocrinology and Metabolism 201095 2672-2679. (https://doi.org/10.1210/jc.2009-2605)

64 Rastogi A, Bhadada SK \& Bhansali A. Pregnancy and tumor outcomes in infertile women with macroprolactinoma on cabergoline therapy. Gynecological Endocrinology 201733 270-273. (https://doi.org/10.1080/ 09513590.2016.1254177)

65 Ricci G, Giolo E, Nucera G, Pozzobon C, de Seta F \& Guaschino S. Pregnancy in hyperprolactinemic infertile women treated with vaginal bromocriptine: report of two cases and review of the literature. Gynecologic and Obstetric Investigation 200151 266-270. (https://doi. org/10.1159/000058062)

66 Saunders NJ. Prolactinoma during pregnancy causing compression symptoms responding to bromocriptine therapy. Postgraduate Medical Journal 198561 829-830. (https://doi.org/10.1136/pgmj.61.719.829)

67 Shahzad H, Sheikh A \& Sheikh L. Cabergoline therapy for macroprolactinoma during pregnancy: a case report. BMC Research Notes 20125 606. (https://doi.org/10.1186/1756-0500-5-606)

68 Tan SL \& Jacobs HS. Rapid regression through bromocriptine therapy of a suprasellar extending prolactinoma during pregnancy. International Journal of Gynaecology and Obstetrics 198624 209-215. (https://doi.org/10.1016/0020-7292(86)90099-8)

69 Trokoudes KM, Walfish PG, Holgate RC, Pritzker KP, Schwartz ML \& Kovacs K. Sellar enlargement with hyperprolactinemia and a Rathke's pouch cyst. JAMA 1978240 471-473. (https://doi.org/10.1001/ jama.240.5.471)

70 van Roon E, van der Vijver JC, Gerretsen G, Hekster RE \& Wattendorff RA. Rapid regression of a suprasellar extending prolactinoma after bromocriptine treatment during pregnancy. Fertility and Sterility 198136 173-177. (https://doi.org/10.1016/s00150282(16)45674-8)

71 Zarate A, Canales ES, Alger M \& Forsbach G. The effect of pregnancy and lactation on pituitary prolactin-secreting tumours. Acta Endocrinologica 197992 407-412. (https://doi.org/10.1530/ acta.0.0920407)

72 Corenblum B. Successful outcome of ergocryptine-induced pregnancies in twenty-one women with prolactin-secreting pituitary adenomas. Fertility and Sterility 197932 183-186. (https://doi. org/10.1016/s0015-0282(16)44177-4)

73 Jones J, Bashir T, Olney J \& Wheatley T. Cabergoline treatment for a large macroprolactinoma throughout pregnancy. Journal of Obstetrics and Gynaecology 199717 375-376. (https://doi. org/10.1080/01443619750112916)

74 Jones TH \& Fraser RB. Cabergoline treated hyperprolactinaemia results in pregnancy in a bromocriptine intolerant patient after seventeen years of infertility. British Journal of Obstetrics and Gynaecology 1994 101 349-350. (https://doi.org/10.1111/j.1471-0528.1994.tb13626.x)

75 Galvao A, Goncalves D, Moreira M, Inocencio G, Silva C \& Braga J. Prolactinoma and pregnancy - a series of cases including pituitary apoplexy. Journal of Obstetrics and Gynaecology 201737 284-287. (https://doi.org/10.1080/01443615.2016.1233946)

76 O'Sullivan SM, Farrant MT, Ogilvie CM, Gunn AJ \& Milsom SR. An observational study of pregnancy and post-partum outcomes in women with prolactinoma treated with dopamine agonists. Australian and New Zealand Journal of Obstetrics and Gynaecology 202060 405-411. (https://doi.org/10.1111/ajo.13070)

77 Janssen NM, Dreyer K \& van der Weiden RM. Management of pituitary tumour apoplexy with bromocriptine in pregnancy. JRSM Short Reports 20123 43. (https://doi.org/10.1258/shorts.2012.011144)

78 Sant'Anna BG, Musolino NRC, Gadelha MR, Marques C, Castro M, Elias PCL et al. A Brazilian multicentre study evaluating pregnancies induced by cabergoline in patients harboring prolactinomas. Pituitary $201923120-128$

79 Ampudia X, Puig-Domingo M, Schwarzstein D, Corcoy R, Espinos JJ, Calaf-Alsina J \& Webb SM. Outcome and long-term effects of pregnancy in women with hyperprolactinaemia. European Journal of Obstetrics, Gynecology, and Reproductive Biology 199246 101-107. (https://doi.org/10.1016/0028-2243(92)90253-U)

80 Lebbe M, Hubinont C, Bernard P \& Maiter D. Outcome of 100 pregnancies initiated under treatment with cabergoline in hyperprolactinaemic women. Clinical Endocrinology 201073 236-242. (https://doi.org/10.1111/j.1365-2265.2010.03808.x)

81 Auriemma RS, Perone Y, di Sarno A, Grasso LF, Guerra E, Gasperi M, Pivonello R \& Colao A. Results of a single-center observational 10-year survey study on recurrence of hyperprolactinemia after pregnancy and lactation. Journal of Clinical Endocrinology and Metabolism 201398 372-379. (https://doi.org/10.1210/jc.2012-3039)

82 Colao A, Abs R, Barcena DG, Chanson P, Paulus W \& Kleinberg DL. Pregnancy outcomes following cabergoline treatment: extended results from a 12-year observational study. Clinical Endocrinology 2008 68 66-71. (https://doi.org/10.1111/j.1365-2265.2007.03000.x)

83 Stalldecker G, Mallea-Gil MS, Guitelman M, Alfieri A, Ballarino MC, Boero L, Chervin A, Danilowicz K, Diez S, Fainstein-Day P et al. Effects of cabergoline on pregnancy and embryo-fetal development: retrospective study on 103 pregnancies and a review of the literature. Pituitary 201013 345-350. (https://doi.org/10.1007/s11102010-0243-6)

84 Rossi AM, Vilska S \& Heinonen PK. Outcome of pregnancies in women with treated or untreated hyperprolactinemia. European Journal of Obstetrics and Gynecology and Reproductive Biology 199563 143-146. (https://doi.org/10.1016/0301-2115(95)02257-0)

85 Ricci E, Parazzini F, Motta T, Ferrari CI, Colao A, Clavenna A, Rocchi F, Gangi E, Paracchi S, Gasperi M et al. Pregnancy outcome after cabergoline treatment in early weeks of gestation. Reproductive Toxicology 200216 791-793. (https://doi.org/10.1016/s08906238(02)00055-2)

86 Atasu T, Kosebay D \& Aksu F. The role of prolactin in luteal inadequacy: treatment of hyperprolactinaemia with bromocriptine. Current Medical Research and Opinion 198811 56-63. (https://doi. org/10.1185/03007998809111132)

87 Borenstein R, Katz Z, Lancet M, Caspi B \& Ben-David M. Bromocriptine treatment of hyperprolactinemic infertility with ovulatory disturbances. International Journal of Gynaecology and Obstetrics 198018 195-199. (https://doi.org/10.1002/j.1879-3479.1980. tb00280.x)

88 Coulam CB \& Lackore RC. Pregnancy associated with the empty sella syndrome and hyperprolactinemia. Fertility and Sterility 197931 220-223. (https://doi.org/10.1016/s0015-0282(16)43827-6)

89 Georgiev DB \& Dokumov SI. Continuous bromocriptine treatment of empty sella syndrome aggravating pregnancy. A case report. Gynecologic and Obstetric Investigation 199132 243-244. (https://doi. org/10.1159/000293041)

90 Imai T, Yasuda K, Ohta T \& Miura K. 13 Trisomy born to a mother treated with bromocriptine: incidental or not? Tohoku Journal of Experimental Medicine 1987153 233-238. (https://doi.org/10.1620/ tjem.153.233)

91 Mroueh AM \& Siler-Khodr TM. Ovarian refractoriness to gonadotropins in cases of inappropriate lactation: restoration of ovarian function with bromocryptine. Journal of Clinical Endocrinology and Metabolism 197643 1398-1401. (https://doi.org/10.1210/jcem-436-1398)

92 Wiebe RH, Hammond CB \& Handwerger S. Treatment of functional amenorrhea-galactorrhea with 2-bromoergocryptine. Fertility and Sterility 197728 426-433. (https://doi.org/10.1016/s00150282(16)42490-8)

93 Corson SL \& Batzer FR. Pregnancy despite continued elevation of prolactin levels while on bromergocryptine. International Journal of Gynaecology and Obstetrics 198523 105-107. (https://doi. org/10.1016/0020-7292(85)90052-9)

94 Cowden EA \& Thomson JA. Resolution of hyperprolactinaemia after bromocriptine-induced pregnancy. Lancet 19791 613. (https://doi. org/10.1016/s0140-6736(79)91043-2) 
95 Crosignani PG, Reschini E, Peracchi M, d'Alberton A \& Lombroso GC. Pregnancy following metergoline treatment in a patient with hyperprolactinaemia. British Journal of Obstetrics and Gynaecology 197784 386-388. (https://doi.org/10.1111/j.1471-0528.1977. tb12604.x)

96 Isaacs AJ. Resolution of hyperprolactinaemia after bromocriptineinduced pregnancy. Lancet 19791 784-785. (https://doi.org/10.1016/ s0140-6736(79)91247-9)

97 al-Suleiman SA, Najashi S, Rahman J \& Rahman MS. Outcome of treatment with bromocriptine in patients with hyperprolactinaemia. Australian and New Zealand Journal of Obstetrics and Gynaecology 1989 29 176-179. (https://doi.org/10.1111/j.1479-828x.1989.tb01712.x)

98 Bergh T, Nillius SJ \& Wide L. Bromocriptine treatment of 42 hyperprolactinaemic women with secondary amenorrhoea. Acta Endocrinologica $1978 \mathbf{8 8} 435-451$. (https://doi.org/10.1530/ acta.0.0880435)

99 Berinder K, Hulting AL, Granath F, Hirschberg AL \& Akre O. Parity, pregnancy and neonatal outcomes in women treated for hyperprolactinaemia compared with a control group. Clinical Endocrinology 200767 393-397. (https://doi.org/10.1111/j.13652265.2007.02897.x)

100 Kermans G, Dhont M \& Vandekerckhove D. Long-term follow-up of treated and untreated hyperprolactinaemic patients. Journal of Obstetrics and Gynaecology 19855 174-181. (https://doi. org/10.3109/01443618509067744)

101 Kletzky OA, Marrs RP \& Davajan V. Management of patients with hyperprolactinemia and normal or abnormal tomograms. American Journal of Obstetrics and Gynecology 1983147 528-532. (https://doi. org/10.1016/0002-9378(83)90010-8)

102 Mornex R, Orgiazzi J, Hugues B, Gagnaire JC \& Claustrat B Normal pregnancies after treatment of hyperprolactinemia with bromoergocryptine, despite suspected pituitary tumors. Journal of Clinical Endocrinology and Metabolism 197847 290-295. (https://doi. org/10.1210/jcem-47-2-290)

103 Webster J, Piscitelli G, Polli A, D’Alberton A, Falsetti L, Ferrari C, Fioretti P, Giordano G, L'Hermite M \& Ciccarelli E. The efficacy and tolerability of long-term cabergoline therapy in hyperprolactinaemic disorders: an open, uncontrolled, multicentre study. European Multicentre Cabergoline Study Group. Clinical Endocrinology 199339 323-329. (https://doi.org/10.1111/j.1365-2265.1993.tb02372.x)

104 Weinstein D, Yarkoni S, Schenker JG, Sahar A, Siew FP, Ben-David M $\&$ Polishuk WZ. Conservative management of suspected prolactin secreting pituitary adenoma during pregnancy. European Journal of Obstetrics, Gynecology, and Reproductive Biology 198111 305-312. (https://doi.org/10.1016/0028-2243(81)90031-9)

105 Dolk H, Loane M \& Garne E. The prevalence of congenital anomalies in Europe. Advances in Experimental Medicine and Biology 2010686 349-364. (https://doi.org/10.1007/978-90-481-9485-8_20)

106 Atmaca A, Dagdelen S \& Erbas T. Follow-up of pregnancy in acromegalic women: different presentations and outcomes. Experimental and Clinical Endocrinology and Diabetes 2006114 135-139. (https://doi.org/10.1055/s-2005-873004)

107 Bigazzi M, Ronga R, Lancranjan I, Ferraro S, Branconi F, Buzzoni P, Martorana G, Scarselli GF \& Del Pozo E. A pregnancy in an acromegalic woman during bromocriptine treatment: effects on growth hormone and prolactin in the maternal, fetal, and amniotic compartments. Journal of Clinical Endocrinology and Metabolism 197948 9-12. (https:// doi.org/10.1210/jcem-48-1-9)

108 Braat DD, Veersema S, Assies J \& Schoemaker J. Triplet pregnancy after pulsatile gonadotrophin-releasing hormone treatment in an acromegalic woman. European Journal of Obstetrics, Gynecology, and Reproductive Biology 199454 148-149. (https://doi.org/10.1016/00282243(94)90256-9)

109 Brian SR, Bidlingmaier M, Wajnrajch MP, Weinzimer SA \& Inzucchi SE. Treatment of acromegaly with pegvisomant during pregnancy: maternal and fetal effects. Journal of Clinical Endocrinology and Metabolism 200792 3374-3377. (https://doi.org/10.1210/jc.2007-0997)

110 Caron P, Broussaud S, Bertherat J, Borson-Chazot F, Brue T, CortetRudelli C \& Chanson P. Acromegaly and pregnancy: a retrospective multicenter study of 59 pregnancies in 46 women. Journal of Clinical Endocrinology and Metabolism 201095 4680-4687. (https://doi. org/10.1210/jc.2009-2331)

111 Cheng S, Grasso L, Martinez-Orozco JA, al-Agha R, Pivonello R, Colao A \& Ezzat S. Pregnancy in acromegaly: experience from two referral centers and systematic review of the literature. Clinical Endocrinology 201276 264-271. (https://doi.org/10.1111/j.13652265.2011.04180.x)

112 Colao A, Merola B, Ferone D \& Lombardi G. Extensive personal experience: acromegaly. Journal of Clinical Endocrinology and Metabolism 199782 2777-2781. (https://doi.org/10.1210/ jcem.82.9.4257)

113 Cozzi R, Attanasio R \& Barausse M. Pregnancy in acromegaly: a one-center experience. European Journal of Endocrinology 2006155 279-284. (https://doi.org/10.1530/eje.1.02215)

114 Cundy T, Grundy EN, Melville H \& Sheldon J. Bromocriptine treatment of acromegaly following spontaneous conception. Fertility and Sterility 198442 134-136. (https://doi.org/10.1016/s00150282(16)47971-9)

115 de Menis E, Billeci D, Marton E \& Gussoni G. Uneventful pregnancy in an acromegalic patient treated with slow-release lanreotide: a case report. Journal of Clinical Endocrinology and Metabolism 1999841489. (https://doi.org/10.1210/jcem.84.4.5625-5)

116 Dias M, Boguszewski C, Gadelha M, Kasuki L, Musolino N, Vieira JG \& Abucham J. Acromegaly and pregnancy: a prospective study. European Journal of Endocrinology 2014170 301-310. (https://doi.org/10.1530/ EJE-13-0460)

117 Fassnacht M, Capeller B, Arlt W, Steck T \& Allolio B. Octreotide LAR treatment throughout pregnancy in an acromegalic woman. Clinical Endocrinology 200155 411-415. (https://doi.org/10.1046/j.13652265.2001.01304.x)

118 Hannon AM, Frizelle I, Kaar G, Hunter SJ, Sherlock M, Thompson CJ, O'Halloran DJ \& Irish Pituitary Database Group. Octreotide use for rescue of vision in a pregnant patient with acromegaly. Endocrinology, Diabetes and Metabolism Case Reports 20192019 19-0019. (https://doi. org/10.1530/EDM-19-0019)

119 Hannon AM, O'Shea T, Thompson CA, Hannon MJ, Dineen R, Khattak A, Gibney J, O'Halloran DJ, Hunter S, Thompson CJ et al. Pregnancy in acromegaly is safe and is associated with improvements in IGF-1 concentrations. European Journal of Endocrinology 2019180 K21-K29. (https://doi.org/10.1530/EJE-18-0688)

120 Herman-Bonert V, Seliverstov M \& Melmed S. Pregnancy in acromegaly: successful therapeutic outcome. Journal of Clinical Endocrinology and Metabolism 199883 727-731. (https://doi. org/10.1210/jcem.83.3.4635)

121 Hierl T, Ziegler R \& Kasperk C. Pregnancy in persistent acromegaly. Clinical Endocrinology 200053 262-263. (https://doi.org/10.1046/ j.1365-2265.2000.01058.x)

122 Hisano M, Sakata M, Watanabe N, Kitagawa M, Murashima A \& Yamaguchi K. An acromegalic woman first diagnosed in pregnancy. Archives of Gynecology and Obstetrics 2006274 171-173. (https://doi. org/10.1007/s00404-005-0114-y)

123 Iwai H, Ito H, Ri S, Harada T, Hirota N, Yamauchi T, Miyatake T, Ohno Y \& Aoki N. Type 1 diabetes associated with asymptomatic acromegaly successfully treated with surgery after pregnancy: a case report. Endocrine Journal 200552 413-420. (https://doi.org/10.1507/ endocrj.52.413)

124 Jallad RS, Shimon I, Fraenkel M, Medvedovsky V, Akirov A, Duarte FH $\&$ Bronstein MD. Outcome of pregnancies in a large cohort of women with acromegaly. Clinical Endocrinology $2018 \mathbf{8 8}$ 896-907. (https://doi. org/10.1111/cen.13599) 
125 Jaspers C, Haase R, Pfingsten H, Benker G \& Reinwein D. Long-term treatment of acromegalic patients with repeatable parenteral depotbromocriptine. Clinical Investigator 199371 547-551. (https://doi. org/10.1007/BF00208479)

126 Kasuki L, Neto LV, Takiya CM \& Gadelha MR. Growth of an aggressive tumor during pregnancy in an acromegalic patient. Endocrine Journal 201259 313-319. (https://doi.org/10.1507/endocrj.ej11-0306)

127 Kim SK, Jung JH, Kim JH, Hur KY, Tan AHK, Kim HK, Lee JI, Chung HS \& Kim K. Sustained maintenance of normal insulin-like growth factor-I during pregnancy and successful delivery in an acromegalic patient with octreotide-LAR(R) treatment. Endocrinology and Metabolism 201025 213-216. (https://doi.org/10.3803/ EnM.2010.25.3.213)

128 Landolt AM, Froesch ER \& Konig MP. Spontaneous postoperative normalization of growth hormone levels in two patients with acromegaly not cured by transsphenoidal surgery. Neurosurgery 1988 23 634-637. (https://doi.org/10.1227/00006123-198811000-00015)

129 Landolt AM, Schmid J, Wimpfheimer C, Karlsson ER \& Boerlin V. Successful pregnancy in a previously infertile woman treated with SMS-201-995 for acromegaly. New England Journal of Medicine 1989320 671-672. (https://doi.org/10.1056/NEJM198903093201016)

130 Lau SL, McGrath S, Evain-Brion D \& Smith R. Clinical and biochemical improvement in acromegaly during pregnancy. Journal of Endocrinological Investigation 200831 255-261. (https://doi. org/10.1007/BF03345599)

131 Maffei P, Tamagno G, Nardelli GB, Videau C, Menegazzo C, Milan G, Calcagno A, Martini C, Vettor R, Epelbaum J et al. Effects of octreotide exposure during pregnancy in acromegaly. Clinical Endocrinology 2010 72 668-677. (https://doi.org/10.1111/j.1365-2265.2009.03706.x)

132 Mikhail N. Octreotide treatment of acromegaly during pregnancy. Mayo Clinic Proceedings 200277 297-298. (https://doi. org/10.4065/77.3.297-a)

133 Miyakawa I, Taniyama K, Koike H, Mori N, Nagamine M, Kuribayashi T \& Araki S. Successful pregnancy in an acromegalic patient during 2-Br-alpha-ergocryptine (CB-154) therapy. Acta Endocrinologica 1982 101 333-338. (https://doi.org/10.1530/acta.0.1010333)

134 Montini M, Pagani G, Gianola D, Pagani MD, Piolini R \& Camboni MG. Acromegaly and primary amenorrhea: ovulation and pregnancy induced by SMS 201-995 and bromocriptine. Journal of Endocrinological Investigation 199013 193. (https://doi.org/10.1007/ BF03349537)

135 Mozas J, Ocon E, Lopez de la Torre M, Suarez AM, Miranda JA \& Herruzo AJ. Successful pregnancy in a woman with acromegaly treated with somatostatin analog (octreotide) prior to surgical resection. International Journal of Gynaecology and Obstetrics 199965 71-73. (https://doi.org/10.1016/s0020-7292(98)00221-5)

136 Neal JM. Successful pregnancy in a woman with acromegaly treated with octreotide. Endocrine Practice 20006 148-150. (https://doi. org/10.4158/EP.6.2.148)

137 O'Herlihy C. Pregnancy in an acromegalic after bromocriptine therapy. Irish Journal of Medical Science 1980149 281-282. (https://doi. org/10.1007/BF02939155)

138 Onder E, Aydin Y, Soysal T, Tuna M \& Gungor A. Acromegaly and pregnancy: five new cases. Turkish Journal of Endocrinology and Metabolism 201721 136-139. (https://doi.org/10.25179/tjem.201756497)

139 Persechini ML, Gennero I, Grunenwald S, Vezzosi D, Bennet A \& Caron P. Acromegaly and pregnancy: report of six new cases. Journal de Gynecologie, Obstetrique et Biologie de la Reproduction 201443 704-712. (https://doi.org/10.1016/j.jgyn.2013.04.008)

140 Qureshi A, Kalu E, Ramanathan G, Bano G, Croucher C \& Panahloo A. IVF/ICSI in a woman with active acromegaly: successful outcome following treatment with pegvisomant. Journal of Assisted Reproduction and Genetics 200623 439-442. (https://doi.org/10.1007/s10815-0069077-6)
141 Serri O \& Lanoie G. Successful pregnancy in a woman with acromegaly treated with octreotide long-acting release. Endocrinologist 200313 17-19. (https://doi.org/10.1097/00019616200301000-00005)

142 Takano T, Saito J, Soyama A, Ito H, Iizuka T, Yoshida T \& Nishikawa T. Normal delivery following an uneventful pregnancy in a Japanese acromegalic patient after discontinuation of octreotide long acting release formulation at an early phase of pregnancy. Endocrine Journal 200653 209-212. (https://doi.org/10.1507/endocrj.53.209)

143 Takeuchi K, Funakoshi T, Oomori S \& Maruo T. Successful pregnancy in an acromegalic women treated with octreotide. Obstetrics and Gynecology 199993 848. (https://doi.org/10.1016/s00297844(98)00461-x)

144 Teltayev D, Akshulakov S, Ryskeldiev N, Mustafin K \& Vyacheslav L. Pregnancy in women after successful acromegaly treatment, including surgical removal of pituitary adenoma and postoperative therapy using lanreotide acetate. Gynecological Endocrinology 201733 (Supplement 1) 50-51. (https://doi.org/10.1080/09513590.2017.1404240)

145 Torun AN \& Torun F. A healthy newborn delivered from an active acromegalic woman receiving high-dose long-acting octreotide during her entire pregnancy. Neurosurgery Quarterly 201222 41-42. (https:// doi.org/10.1097/WNQ.0b013e3182277dc6)

146 van der Lely AJ, Gomez R, Heissler JF, Akerblad AC, Jonsson P, Camacho-Hubner C \& Kołtowska-Häggström M. Pregnancy in acromegaly patients treated with pegvisomant. Endocrine 201549 769-773. (https://doi.org/10.1007/s12020-014-0508-3)

147 Vialon M, Grunenwald S, Mouly C, Vezzosi D, Bennet A, Gourdy P \& Caron PJ. Gestational diabetes and acromegaly: single-centre experience of 14 pregnancies. Clinical Endocrinology 201991 805-809. (https://doi.org/10.1111/cen.14097)

148 Wiesli P, Zwimpfer C, Zapf J \& Schmid C. Pregnancy-induced changes in insulin-like growth factor I (IGF-I), insulin-like growth factor binding protein 3 (IGFBP-3), and acid-labile subunit (ALS) in patients with growth hormone (GH) deficiency and excess. Acta Obstetricia et Gynecologica Scandinavica 200685 900-905. (https://doi. org/10.1080/00016340600676532)

149 Williams F, Hunter S, Bradley L, Chahal HS, Storr HL, Akker SA, Kumar AV, Orme SM, Evanson J, Abid N et al. Clinical experience in the screening and management of a large kindred with familial isolated pituitary adenoma due to an aryl hydrocarbon receptor interacting protein (AIP) mutation. Journal of Clinical Endocrinology and Metabolism 201499 1122-1131. (https://doi.org/10.1210/jc.2013-2868)

150 Yap AS, Clouston WM, Mortimer RH \& Drake RF. Acromegaly first diagnosed in pregnancy: the role of bromocriptine therapy. American Journal of Obstetrics and Gynecology 1990163 477-478. (https://doi. org/10.1016/0002-9378(90)91178-f)

151 Luboshitzky R, Dickstein G \& Barzilai D. Bromocriptine-induced pregnancy in an acromegalic patient. JAMA 1980244 584-586. (https://doi.org/10.1001/jama.244.6.584)

152 Berwaerts J, Verhelst J, Mahler C \& Abs R. Cushing's syndrome in pregnancy treated by ketoconazole: case report and review of the literature. Gynecological Endocrinology 199913 175-182. (https://doi. org/10.3109/09513599909167552)

153 Boronat M, Marrero D, Lopez-Plasencia Y, Barber M, Schamann Y $\&$ Novoa FJ. Successful outcome of pregnancy in a patient with Cushing's disease under treatment with ketoconazole during the first trimester of gestation. Gynecological Endocrinology 201127 675-677. (https://doi.org/10.3109/09513590.2010.521268)

154 Cabezon C, Bruno OD, Cohen M, Garcia S \& Gutman RA. Twin pregnancy in a patient with Cushing's disease. Fertility and Sterility 199972 371-372. (https://doi.org/10.1016/s0015-0282(99)00261-7)

155 Costenaro F, Rodrigues TC, de Lima PB, Ruszczyk J, Rollin G \& Czepielewski MA. A successful case of Cushing's disease pregnancy treated with ketoconazole. Gynecological Endocrinology 201531 176-178. (https://doi.org/10.3109/09513590.2014.995615) 
156 Knappe G, Gerl H, Ventz M \& Rohde W. The long-term therapy of hypothalamic-hypophyseal Cushing's syndrome with mitotane (o,p'-DDD). Deutsche Medizinische Wochenschrift 1997122 882-886. (https://doi.org/10.1055/s-2008-1047704)

157 Lindsay JR, Jonklaas J, Oldfield EH \& Nieman LK. Cushing's syndrome during pregnancy: personal experience and review of the literature. Journal of Clinical Endocrinology and Metabolism 200590 3077-3083. (https://doi.org/10.1210/jc.2004-2361)

158 Magkou D, Do Cao C, Bouvattier C, Douillard C, de Marcellus C, Cazabat L, Gérard M, Raffin-Sanson ML \& Young J. Foetal exposure to mitotane/Op'DDD: post-natal study of four children. Clinical Endocrinology 201889 805-812. (https://doi.org/10.1111/cen.13854)

159 Nakhleh A, Saiegh L, Reut M, Ahmad MS, Pearl IW \& Shechner C. Cabergoline treatment for recurrent Cushing's disease during pregnancy. Hormones 201615 453-458. (https://doi.org/10.14310/ horm.2002.1685)

160 Sek KS, Deepak DS \& Lee KO. Use of cabergoline for the management of persistent Cushing's disease in pregnancy. BMJ Case Reports 2017 2017 bcr2016217855. (https://doi.org/10.1136/bcr-2016-217855)

161 Woo I \& Ehsanipoor RM. Cabergoline therapy for Cushing disease throughout pregnancy. Obstetrics and Gynecology 2013122 485-487. (https://doi.org/10.1097/AOG.0b013e31829e398a)

162 Lambert K, Rees K, Seed PT, Dhanjal MK, Knight M, McCance DR \& Williamson C. Macroprolactinomas and nonfunctioning pituitary adenomas and pregnancy outcomes. Obstetrics and Gynecology 2017 129 185-194. (https://doi.org/10.1097/AOG.0000000000001747)

163 Bergh T, Nillius SJ, Enoksson P, Larsson SG \& Wide L. Bromocriptine-induced pregnancies in women with large prolactinomas. Clinical Endocrinology 198217 625-631. (https://doi. org/10.1111/j.1365-2265.1982.tb01636.x)

164 Crosignani PG, Mattei AM, Severini V, Cavioni V, Maggioni P \& Testa G. Long-term effects of time, medical treatment and pregnancy in 176 hyperprolactinemic women. European Journal of Obstetrics, Gynecology, and Reproductive Biology 199244 175-180. (https://doi. org/10.1016/0028-2243(92)90094-f)

165 Holmgren U, Bergstrand G, Hagenfeldt K \& Werner S. Women with prolactinoma - effect of pregnancy and lactation on serum prolactin and on tumour growth. Acta Endocrinologica 1986111 452-459. (https://doi.org/10.1530/acta.0.1110452)

166 Randall S, Laing I, Chapman AJ, Shalet SM, Beardwell CG, Kelly WF \& Davies D. Pregnancies in women with hyperprolactinaemia: obstetric and endocrinological management of 50 pregnancies in 37 women. British Journal of Obstetrics and Gynaecology 198289 20-23. (https:// doi.org/10.1111/j.1471-0528.1982.tb04628.x)

167 Samaan NA, Leavens ME, Sacca R, Smith K \& Schultz PN. The effects of pregnancy on patients with hyperprolactinemia. American Journal of Obstetrics and Gynecology 1984148 466-473. (https://doi. org/10.1016/0002-9378(84)90728-2)

168 Abbassy M, Kshettry VR, Hamrahian AH, Johnston PC, Dobri GA, Avitsian R, Woodard TD \& Recinos PF. Surgical management of recurrent Cushing's disease in pregnancy: a case report. Surgical Neurology International 20156 (Supplement 25) S640-S645. (https:// doi.org/10.4103/2152-7806.170472)

169 Casson IF, Davis JC, Jeffreys RV, Silas JH, Williams J \& Belchetz PE. Successful management of Cushing's disease during pregnancy by transsphenoidal adenectomy. Clinical Endocrinology 198727 423-428. (https://doi.org/10.1111/j.1365-2265.1987.tb01169.x)

170 Chaiamnuay S, Moster M, Katz MR \& Kim YN. Successful management of a pregnant woman with a TSH secreting pituitary adenoma with surgical and medical therapy. Pituitary 20036 109-113. (https://doi. org/10.1023/b:pitu.0000004802.47010.00)

171 Coyne TJ, Atkinson RL \& Prins JB. Adrenocorticotropic hormonesecreting pituitary tumor associated with pregnancy: case report. Neurosurgery 199231 953-955; discussion 5. (https://doi. org/10.1227/00006123-199211000-00021)
172 Freeman R, Wezenter B, Silverstein M, Kuo D, Weiss KL, Kantrowitz AB \& Schubart UK. Pregnancy-associated subacute hemorrhage into a prolactinoma resulting in diabetes insipidus. Fertility and Sterility 199258 427-429. (https://doi.org/10.1016/s00150282(16)55219-4)

173 Hayes AR, O'Sullivan AJ \& Davies MA. A case of pituitary apoplexy in pregnancy. Endocrinology, Diabetes and Metabolism Case Reports 2014 2014 140043. (https://doi.org/10.1530/EDM-14-0043)

174 Jolly K, Darr A, Arlt W, Ahmed S \& Karavitaki N. Surgery for Cushing's disease in pregnancy: our experience and a literature review. Annals of the Royal College of Surgeons of England 2019101 e26-e31. (https://doi. org/10.1308/rcsann.2018.0175)

175 Kita D, Hayashi Y, Sano H, Takamura T, Hayashi Y, Tachibana O \& Hamada J. Postoperative diabetes insipidus associated with pituitary apoplexy during pregnancy. Neuro Endocrinology Letters 201233 107-112.

176 Koshy TG, Rajaratnam S, Mathews JE \& Rajshekhar V. Acromegaly in pregnancy. Indian Journal of Endocrinology and Metabolism 201216 1029-1031. (https://doi.org/10.4103/2230-8210.103033)

177 Lamberts SW, Klijn JG, de Lange SA, Singh R, Stefanko SZ \& Birkenhager JC. The incidence of complications during pregnancy after treatment of hyperprolactinemia with bromocriptine in patients with radiologically evident pituitary tumors. Fertility and Sterility 197931 614-619. (https://doi.org/10.1016/s00150282(16)44050-1)

178 Lunardi P, Rizzo A, Missori P \& Fraioli B. Pituitary apoplexy in an acromegalic woman operated on during pregnancy by transphenoidal approach. International Journal of Gynaecology and Obstetrics 199134 71-74. (https://doi.org/10.1016/0020-7292(91)90542-d)

179 Mellor A, Harvey RD, Pobereskin LH \& Sneyd JR. Cushing's disease treated by trans-sphenoidal selective adenomectomy in midpregnancy. British Journal of Anaesthesia 199880 850-852. (https://doi. org/10.1093/bja/80.6.850)

180 Nishio S, Morioka T, Suzuki S, Takeshita I, Ikezaki K, Fukui M \& Nakano H. Primary brain tumours manifesting during pregnancy: presentation of six cases and a review of the literature. Journal of Clinical Neuroscience 19963 334-337. (https://doi.org/10.1016/s09675868(96)90029-6)

181 Oguz SH, Soylemezoglu F, Dagdelen S \& Erbas T. A case of atypical macroprolactinoma presenting with pituitary apoplexy during pregnancy and review of the literature. Gynecological Endocrinology 202036 109-116. (https://doi.org/10.1080/09513590.2 019.1650339)

182 Querol Ripoll R, Camara Gomez R, del Olmo Garcia M, Simal Julian JA $\&$ Merino Torres JF. Pituitary apoplexy in a pregnant woman with cystic microprolactinoma. Endocrinologia y Nutricion 201562 200-202 (https://doi.org/10.1016/j.endonu.2015.01.007)

183 Ross RJ, Chew SL, Perry L, Erskine K, Medbak S \& Afshar F. Diagnosis and selective cure of Cushing's disease during pregnancy by transsphenoidal surgery. European Journal of Endocrinology 1995132 722-726. (https://doi.org/10.1530/eje.0.1320722)

184 Sahli R \& Christ E. Pregnancy in active acromegaly. Deutsche Medizinische Wochenschrift 2008133 2328-2331. (https://doi org/10.1055/s-0028-1100923)

185 Tandon A, Alzate J, LaSala P \& Fried MP. Endoscopic endonasal transsphenoidal resection for pituitary apoplexy during the third trimester of pregnancy. Surgery Research and Practice 20142014397131. (https://doi.org/10.1155/2014/397131)

186 Verdugo C, Alegria J, Grant C, Briano E, Gonzalez MI, Meza H, Amthauer N, Paiva O, Vigueras R \& Madariaga J. Cushing's disease treatment with transsphenoidal surgery during pregnancy. Revista medica de Chile 2004132 75-80. (https://doi.org/10.4067/s003498872004000100012)

187 Witek P, Zielinski G, Maksymowicz M \& Zgliczynski W. Transsphenoidal surgery for a life-threatening prolactinoma 
apoplexy during pregnancy. Neuro Endocrinology Letters 201233 483-488.

188 Xia Y, Ma X, Griffiths BB \& Luo Y. Neurosurgical anesthesia for a pregnant woman with macroprolactinoma: a case report. Medicine 201897 e12360. (https://doi.org/10.1097/MD.0000000000012360)

189 Yamaguchi R, Kohga H, Tosaka M, Sekine A, Mizushima K, Harigaya Y $\&$ Yoshimoto Y. A case of optic neuritis concomitant with pituitary tumor during pregnancy. World Neurosurgery 201693 488.e1-488.e4. (https://doi.org/10.1016/j.wneu.2016.06.103)

190 Cecchino GN, Canillas GM, Cruz M \& García-Velasco JA. Impact of hypogonadotropic hypogonadism on ovarian reserve and response. Journal of Assisted Reproduction and Genetics 201936 2379-2384. (https://doi.org/10.1007/s10815-019-01587-7)

191 Castinetti F, Dufour H, Gaillard S, Jouanneau E, Vasiljevic A, Villa C $\&$ Trouillas J. Non-functioning pituitary adenoma: when and how to operate? What pathologic criteria for typing? Annales d'Endocrinologie 201576 220-227. (https://doi.org/10.1016/j.ando.2015.04.007)

192 Murad MH, Fernandez-Balsells MM, Barwise A, Gallegos-Orozco JF, Paul A, Lane MA, Lampropulos JF, Natividad I, Perestelo-Pérez L, Ponce de León-Lovatón PG et al. Outcomes of surgical treatment for nonfunctioning pituitary adenomas: a systematic review and meta-analysis. Clinical Endocrinology 201073 777-791. (https://doi. org/10.1111/j.1365-2265.2010.03875.x)

193 Lamba N, Noormohamed N, Simjian T, Alsheikh MY, Jamal A, Doucette J, Zaidi H, Smith TR \& Mekary RA. Fertility after transsphenoidal surgery in patients with prolactinomas: a metaanalysis. Clinical Neurology and Neurosurgery 2019 176 53-60. (https:// doi.org/10.1016/j.clineuro.2018.11.024)

194 Arafah BM, Kailani SH, Nekl KE, Gold RS \& Selman WR. Immediate recovery of pituitary function after transsphenoidal resection of pituitary macroadenomas. Journal of Clinical Endocrinology and Metabolism 199479 348-354. (https://doi.org/10.1210/ jcem.79.2.8045946)

195 Magro E, Graillon T, Lassave J, Castinetti F, Boissonneau S, Tabouret E, Fuentes S, Velly L, Gras R \& Dufour H. Complications related to the endoscopic endonasal transsphenoidal approach for nonfunctioning pituitary macroadenomas in 300 consecutive patients. World Neurosurgery 201689 442-453. (https://doi.org/10.1016/j. wneu.2016.02.059)

196 Vila G \& Fleseriu M. Fertility and pregnancy in women with hypopituitarism: a systematic literature review. Journal of Clinical Endocrinology and Metabolism 2020105 dgz112. (https://doi. org/10.1210/clinem/dgz112)

197 Hall R, Manski-Nankervis J, Goni N, Davies MC \& Conway GS. Fertility outcomes in women with hypopituitarism. Clinical Endocrinology 2006 65 71-74. (https://doi.org/10.1111/j.1365-2265.2006.02550.x)

198 de Boer JA, Schoemaker J \& van der Veen EA. Impaired reproductive function in women treated for growth hormone deficiency during childhood. Clinical Endocrinology 199746 681-689. (https://doi. org/10.1046/j.1365-2265.1997.1800999.x)

199 Vila G \& Luger A. Growth hormone deficiency and pregnancy: any role for substitution? Minerva Endocrinologica 201843 451-457. (https://doi.org/10.23736/S0391-1977.18.02834-1)

200 Fleseriu M, Hashim IA, Karavitaki N, Melmed S, Murad MH, Salvatori R \& Samuels MH. Hormonal replacement in hypopituitarism in adults: an Endocrine Society Clinical Practice Guideline. Journal of Clinical Endocrinology and Metabolism 2016101 3888-3921. (https://doi. org/10.1210/jc.2016-2118)

201 Correa FA, Bianchi PHM, Franca MM, Otto AP, Rodrigues RJM, Ejzenberg D, Serafini PC, Baracat EC, Francisco RPV, Brito VN et al. Successful pregnancies after adequate hormonal replacement in patients with combined pituitary hormone deficiencies. Journal of the Endocrine Society 20171 1322-1330. (https://doi.org/10.1210/js.2017-00005)

202 Giampietro A, Milardi D, Bianchi A, Fusco A, Cimino V, Valle D, Marana R, Pontecorvi A \& De Marinis L. The effect of treatment with growth hormone on fertility outcome in eugonadal women with growth hormone deficiency: report of four cases and review of the literature. Fertility and Sterility 200991 930.e7-930.e11. (https://doi. org/10.1016/j.fertnstert.2008.09.065)

203 Salle A, Klein M, Pascal-Vigneron V, Dousset B, Leclere J \& Weryha G. Successful pregnancy and birth after sequential cotreatment with growth hormone and gonadotropins in a woman with panhypopituitarism: a new treatment protocol. Fertility and Sterility 200074 1248-1250. (https://doi.org/10.1016/s0015-0282(00)01619-8)

204 Daniel A, Ezzat S \& Greenblatt E. Adjuvant growth hormone for ovulation induction with gonadotropins in the treatment of a woman with hypopituitarism. Case Reports in Endocrinology 20122012356429. (https://doi.org/10.1155/2012/356429)

205 Albu D \& Albu A. Is growth hormone administration essential for in vitro fertilization treatment of female patients with growth hormone deficiency? Systems Biology in Reproductive Medicine 201965 71-74. (https://doi.org/10.1080/19396368.2018.1492044)

206 Rodriguez-Purata J, Sekhon L, Lee JA, Whitehouse MC, Copperman AB \& Sandler B. Fertility outcomes in women with hypopituitarism (HP) who undergo art treatment. Fertility and Sterility 2016106 e244-e245. (https://doi.org/10.1016/j. fertnstert.2016.07.707)

207 Chanson P \& Schaison G. Pituitary apoplexy caused by GnRHagonist treatment revealing gonadotroph adenoma. Journal of Clinical Endocrinology and Metabolism 199580 2267-2268. (https://doi. org/10.1210/jcem.80.7.7608291)

208 Stefaniak A, Domitrz J, Siewko K, Szelachowska M, Kretowski A \& Stachura-Matyjewicz A. Pituitary adenoma and apoplexy during GnRH agonist treatment for IVF - case report. Gynecological Endocrinology 2020 561-563. (https://doi.org/10.1080/09513590.2019. 1706086)

209 Overton CE, Davis CJ, West C, Davies MC \& Conway GS. High risk pregnancies in hypopituitary women. Human Reproduction 200217 1464-1467. (https://doi.org/10.1093/humrep/17.6.1464)

210 Bornstein SR, Allolio B, Arlt W, Barthel A, Don-Wauchope A, Hammer GD, Husebye ES, Merke DP, Murad MH, Stratakis CA et al. Diagnosis and treatment of primary adrenal insufficiency: an Endocrine Society clinical practice guideline. Journal of Clinical Endocrinology and Metabolism 2016101 364-389. (https://doi. $\operatorname{org} / 10.1210 /$ jc.2015-1710)

211 Lindsay JR \& Nieman LK. The hypothalamic-pituitary-adrenal axis in pregnancy: challenges in disease detection and treatment. Endocrine Reviews 200526 775-799. (https://doi.org/10.1210/er.2004-0025)

213 Persani L, Brabant G, Dattani M, Bonomi M, Feldt-Rasmussen U, Fliers E, Gruters A, Maiter D, Schoenmakers N \& van Trotsenburg ASP. 2018 European Thyroid Association (ETA) guidelines on the diagnosis and management of central hypothyroidism. European Thyroid Journal 20187 225-237. (https://doi.org/10.1159/000491388)

213 Beitins IZ, Bayard F, Ances IG, Kowarski A \& Migeon CJ. The transplacental passage of prednisone and prednisolone in pregnancy near term. Journal of Pediatrics 197281 936-945. (https://doi. org/10.1016/s0022-3476(72)80547-x)

214 Anand G \& Beuschlein F. Management of endocrine disease: fertility, pregnancy and lactation in women with adrenal insufficiency. European Journal of Endocrinology 2018178 R45-R53. (https://doi. org/10.1530/EJE-17-0975)

215 Refardt J \& Christ-Crain M. Diabetes insipidus in pregnancy: how to advice the patient? Minerva Endocrinologica 201843 458-464. (https:// doi.org/10.23736/S0391-1977.18.02807-9)

216 Vila G, Akerblad AC, Mattsson AF, Riedl M, Webb SM, Hana V, Nielsen EH, Biller BM \& Luger A. Pregnancy outcomes in women with growth hormone deficiency. Fertility and Sterility 20151041210. e1-1217.e1. (https://doi.org/10.1016/j.fertnstert.2015.07.1132)

217 Lebbe M \& Arlt W. What is the best diagnostic and therapeutic management strategy for an Addison patient during pregnancy? Clinical Endocrinology 201378 497-502. (https://doi.org/10.1111/ cen.12097) 
218 Committee opinion no. 723: guidelines for diagnostic imaging during pregnancy and lactation. Obstetrics and Gynecology 2017130 e210-e216. (https://doi.org/10.1097/AOG.0000000000002355)

219 Patenaude Y, Pugash D, Lim K, Morin L, Diagnostic Imaging Committee, Lim K, Bly S, Butt K, Cargill Y, Davies G, Davies G et al. The use of magnetic resonance imaging in the obstetric patient. Journal of Obstetrics and Gynaecology Canada 201436 349-363. (https://doi. org/10.1016/s1701-2163(15)30612-5)

220 Webb JA, Thomsen HS, Morcos SK \& Members of Contrast Media Safety Committee of European Society of Urogenital Radiology. The use of iodinated and gadolinium contrast media during pregnancy and lactation. European Radiology 200515 1234-1240. (https://doi. org/10.1007/s00330-004-2583-y)

221 Prayer D, Malinger G, Brugger PC, Cassady C, de Catte L, de Keersmaecker B, Fernandes GL, Glanc P, Gonçalves LF, Gruber GM et al. ISUOG practice guidelines: performance of fetal magnetic resonance imaging. Ultrasound in Obstetrics and Gynecology 201749 671-680. (https://doi.org/10.1002/uog.17412)

222 Kupersmith MJ, Rosenberg C \& Kleinberg D. Visual loss in pregnant women with pituitary adenomas. Annals of Internal Medicine $1994 \mathbf{1 2 1}$ 473-477. (https://doi.org/10.7326/0003-4819-121-7-199410010-00001)

223 Graillon T, Cuny T, Castinetti F, Courbière B, Cousin M, Albarel F, Morange I, Bruder N, Brue T \& Dufour H. Surgical indications for pituitary tumors during pregnancy: a literature review. Pituitary 2020 23 189-199. (https://doi.org/10.1007/s11102-019-01004-3)

224 Huang W \& Molitch ME. Pituitary tumors in pregnancy. Endocrinology and Metabolism Clinics of North America 201948 569-581. (https://doi. $\operatorname{org} / 10.1016 /$ j.ecl.2019.05.004)

225 Heesen M \& Klimek M. Nonobstetric anesthesia during pregnancy. Current Opinion in Anaesthesiology 201629 297-303. (https://doi. org/10.1097/ACO.0000000000000311)

226 Chowdhury T, Chowdhury M, Schaller B, Cappellani RB \& Daya J. Perioperative considerations for neurosurgical procedures in the gravid patient: continuing professional development. Canadian Journal of Anaesthesia 201360 1139-1155. (https://doi.org/10.1007/ s12630-013-0031-7)

227 Laviv Y, Bayoumi A, Mahadevan A, Young B, Boone M \& Kasper EM. Meningiomas in pregnancy: timing of surgery and clinical outcomes as observed in 104 cases and establishment of a best management strategy. Acta Neurochirurgica 2018160 1521-1529. (https://doi. org/10.1007/s00701-017-3146-8)

228 Kubler K, Klingmuller D, Gembruch U \& Merz WM. High-risk pregnancy management in women with hypopituitarism. Journal of Perinatology 200929 89-95. (https://doi.org/10.1038/jp.2008.116)

229 Woodcock T, Barker P, Daniel S, Fletcher S, Wass JAH, Tomlinson JW, Misra U, Dattani M, Arlt W \& Vercueil A. Guidelines for the management of glucocorticoids during the peri-operative period for patients with adrenal insufficiency: guidelines from the Association of Anaesthetists, the Royal College of Physicians and the Society for Endocrinology UK. Anaesthesia 202075 654-663. (https://doi. org/10.1111/anae.14963)

230 Maiter D. Prolactinoma and pregnancy: from the wish of conception to lactation. Annales d'Endocrinologie 201677 128-134. (https://doi. org/10.1016/j.ando.2016.04.001)

231 Souter I, Baltagi LM, Toth TL \& Petrozza JC. Prevalence of hyperprolactinemia and abnormal magnetic resonance imaging findings in a population with infertility. Fertility and Sterility 201094 1159-1162. (https://doi.org/10.1016/j.fertnstert.2009.12.017)

232 Melmed S, Casanueva FF, Hoffman AR, Kleinberg DL, Montori VM, Schlechte JA, Wass JA \& Endocrine Society. Diagnosis and treatment of hyperprolactinemia: an Endocrine Society Clinical Practice Guideline. Journal of Clinical Endocrinology and Metabolism 201196 273-288. (https://doi.org/10.1210/jc.2010-1692)

233 Casanueva FF, Molitch ME, Schlechte JA, Abs R, Bonert V, Bronstein MD, Brue T, Cappabianca P, Colao A, Fahlbusch R et al.
Guidelines of the pituitary society for the diagnosis and management of prolactinomas. Clinical Endocrinology 200665 265-273. (https://doi. $\operatorname{org} / 10.1111 /$ j.1365-2265.2006.02562.x)

234 Gillam MP, Molitch ME, Lombardi G \& Colao A. Advances in the treatment of prolactinomas. Endocrine Reviews 200627 485-534. (https://doi.org/10.1210/er.2005-9998)

235 Chanson P \& Maiter D. Prolactinoma. In The Pituitary, 4th ed., pp. 467-513. Ed S Melmed, 2017.

236 Wang AT, Mullan RJ, Lane MA, Hazem A, Prasad C, Gathaiya NW, Fernández-Balsells MM, Bagatto A, Coto-Yglesias F, Carey J et al. Treatment of hyperprolactinemia: a systematic review and meta-analysis. Systematic Reviews 20121 33. (https://doi.org/10.1186/2046-4053-1-33)

237 Webster J, Piscitelli G, Polli A, Ferrari CI, Ismail I \& Scanlon MF. A comparison of cabergoline and bromocriptine in the treatment of hyperprolactinemic amenorrhea. Cabergoline Comparative Study Group. New England Journal of Medicine 1994331 904-909. (https:// doi.org/10.1056/NEJM199410063311403)

238 Verhelst J, Abs R, Maiter D, van den Bruel A, Vandeweghe M, Velkeniers B, Mockel J, Lamberigts G, Petrossians P, Coremans P et al. Cabergoline in the treatment of hyperprolactinemia: a study in 455 patients. Journal of Clinical Endocrinology and Metabolism 199984 2518-2522. (https://doi.org/10.1210/jcem.84.7.5810)

239 di Sarno A, Landi ML, Cappabianca P, di Salle F, Rossi FW, Pivonello R, Di Somma C, Faggiano A, Lombardi G \& Colao A. Resistance to cabergoline as compared with bromocriptine in hyperprolactinemia: prevalence, clinical definition, and therapeutic strategy. Journal of Clinical Endocrinology and Metabolism 200186 5256-5261. (https://doi. org/10.1210/jcem.86.11.8054)

240 Buchfelder M, Zhao Y \& Schlaffer SM. Surgery for prolactinomas to date. Neuroendocrinology 2019109 77-81. (https://doi. org/10.1159/000497331)

241 Zamanipoor Najafabadi AH, Zandbergen IM, de Vries F, Broersen LHA, van den Akker-van Marle ME, Pereira AM, Peul WC, Dekkers OM, van Furth WR \& Biermasz NR. Surgery as a viable alternative first-line treatment for prolactinoma patients. A systematic review and metaanalysis. Journal of Clinical Endocrinology and Metabolism 2020105 e32-e41. (https://doi.org/10.1210/clinem/dgz144)

242 Primeau V, Raftopoulos C \& Maiter D. Outcomes of transsphenoidal surgery in prolactinomas: improvement of hormonal control in dopamine agonist-resistant patients. European Journal of Endocrinology 2012166 779-786. (https://doi.org/10.1530/EJE-11-1000)

243 Honegger J, Nasi-Kordhishti I, Aboutaha N \& Giese S. Surgery for prolactinomas: a better choice? Pituitary 202023 45-51. (https://doi. org/10.1007/s11102-019-01016-z)

244 Cohain JS, Buxbaum RE \& Mankuta D. Spontaneous first trimester miscarriage rates per woman among parous women with 1 or more pregnancies of 24 weeks or more. BMC Pregnancy and Childbirth 2017 17 437. (https://doi.org/10.1186/s12884-017-1620-1)

245 Moorthie S, Blencowe H, Darlison MW, Lawn J, Morris JK, Modell B, Congenital Disorders Expert Group, Bittles AH, Blencowe H, Christianson A, Christianson A et al. Estimating the birth prevalence and pregnancy outcomes of congenital malformations worldwide. Journal of Community Genetics 20189 387-396. (https://doi. org/10.1007/s12687-018-0384-2)

246 Webster J. A comparative review of the tolerability profiles of dopamine agonists in the treatment of hyperprolactinaemia and inhibition of lactation. Drug Safety 199614 228-238. (https://doi. org/10.2165/00002018-199614040-00003)

247 Faje A, Chunharojrith P, Nency J, Biller BM, Swearingen B \& Klibanski A. Dopamine agonists can reduce cystic prolactinomas. Journal of Clinical Endocrinology and Metabolism 2016101 3709-3715. (https://doi.org/10.1210/jc.2016-2008)

248 Schlechte JA. Clinical practice. Prolactinoma. New England Journal of Medicine 2003349 2035-2041. (https://doi.org/10.1056/ NEJMcp025334) 
249 Tyson JE, Hwang P, Guyda H \& Friesen HG. Studies of prolactin secretion in human pregnancy. American Journal of Obstetrics and Gynecology 1972113 14-20. (https://doi.org/10.1016/00029378(72)90446-2)

250 Rigg LA, Lein A \& Yen SS. Pattern of increase in circulating prolactin levels during human gestation. American Journal of Obstetrics and Gynecology 1977129 454-456. (https://doi.org/10.1016/00029378(77)90594-4)

251 Quigley MM, Hammond CB \& Handwerger S. Prolactin after gonadotropin-induced pregnancy. Fertility and Sterility 197627 1165-1170. (https://doi.org/10.1016/S0015-0282(16)42134-5)

252 Biswas S \& Rodeck CH. Plasma prolactin levels during pregnancy. British Journal of Obstetrics and Gynaecology 197683 683-687. (https:// doi.org/10.1111/j.1471-0528.1976.tb00913.x)

253 Divers Jr WA \& Yen SS. Prolactin-producing microadenomas in pregnancy. Obstetrics and Gynecology 198362 425-429.

254 Diri H, Tanriverdi F, Karaca Z, Senol S, Unluhizarci K, Durak AC, Atmaca $\mathrm{H} \&$ Kelestimur F. Extensive investigation of 114 patients with Sheehan's syndrome: a continuing disorder. European Journal of Endocrinology 2014171 311-318. (https://doi.org/10.1530/EJE-140244)

255 Barraud S, Guedra L, Delemer B, Raverot G, Ancelle D, Fevre A, Jouanneau E, Litré CF, Wolak-Thierry A, Borson-Chazot F et al. Evolution of macroprolactinomas during pregnancy: a cohort study of 85 pregnancies. Clinical Endocrinology 202092 421-427. (https://doi. org/10.1111/cen.14162)

256 Ikegami H, Aono T, Koizumi K, Koike K, Fukui H \& Tanizawa O. Relationship between the methods of treatment for prolactinomas and the puerperal lactation. Fertility and Sterility 198747 867-869. (https://doi.org/10.1016/s0015-0282(16)59182-1)

257 Grynberg M, Salenave S, Young J \& Chanson P. Female gonadal function before and after treatment of acromegaly. Journal of Clinical Endocrinology and Metabolism 201095 4518-4525. (https://doi. org/10.1210/jc.2009-2815)

258 Colao A, Grasso LFS, Giustina A, Melmed S, Chanson P, Pereira AM \& Pivonello R. Acromegaly. Nature Reviews: Disease Primers 2019520. (https://doi.org/10.1038/s41572-019-0071-6)

259 Buchfelder M \& Schlaffer SM. The surgical treatment of acromegaly. Pituitary 201720 76-83. (https://doi.org/10.1007/s11102-016-0765-7)

260 Chanson P, Vialon M \& Caron P. An update on clinical care for pregnant women with acromegaly. Expert Review of Endocrinology and Metabolism 201914 85-96. (https://doi.org/10.1080/17446651.2019.157 1909)

261 Katznelson L, Laws Jr ER, Melmed S, Molitch ME, Murad MH, Utz A, Wass JA \& Endocrine Society. Acromegaly: an Endocrine Society Clinical Practice Guideline. Journal of Clinical Endocrinology and Metabolism 201499 3933-3951. (https://doi.org/10.1210/jc.2014-2700)

262 Liao S, Vickers MH, Stanley JL, Baker PN \& Perry JK. Human placental growth hormone variant in pathological pregnancies. Endocrinology 2018159 2186-2198. (https://doi.org/10.1210/en.2018-00037)

263 Abucham J, Bronstein MD \& Dias ML. Management of endocrine disease: acromegaly and pregnancy: a contemporary review. European Journal of Endocrinology 2017177 R1-R12. (https://doi.org/10.1530/ EJE-16-1059)

264 Persechini ML, Gennero I, Grunenwald S, Vezzosi D, Bennet A \& Caron P. Decreased IGF-1 concentration during the first trimester of pregnancy in women with normal somatotroph function. Pituitary 201518 461-464. (https://doi.org/10.1007/s11102-014-0596-3)

265 Chellakooty M, Vangsgaard K, Larsen T, Scheike T, Falck-Larsen J, Legarth J, Andersson AM, Main KM, Skakkebaek NE \& Juul A.
A longitudinal study of intrauterine growth and the placental growth hormone (GH)-insulin-like growth factor I axis in maternal circulation: association between placental GH and fetal growth. Journal of Clinical Endocrinology and Metabolism 200489 384-391. (https://doi.org/10.1210/jc.2003-030282)

266 Cheng V, Faiman C, Kennedy L, Khoury F, Hatipoglu B, Weil R \& Hamrahian A. Pregnancy and acromegaly: a review. Pituitary 201215 59-63. (https://doi.org/10.1007/s11102-011-0330-3)

267 Okada Y, Morimoto I, Ejima K, Yoshida K, Kashimura M, Fujihira T $\&$ Eto $S$. A case of active acromegalic woman with a marked increase in serum insulin-like growth factor-1 levels after delivery. Endocrine Journal 199744 117-120. (https://doi.org/10.1507/endocri.44.117)

268 Bronstein MD, Paraiba DB \& Jallad RS. Management of pituitary tumors in pregnancy. Nature Reviews: Endocrinology 20117 301-310. (https://doi.org/10.1038/nrendo.2011.38)

269 Nieman LK, Biller BM, Findling JW, Newell-Price J, Savage MO, Stewart PM \& Montori VM. The diagnosis of Cushing's syndrome: an Endocrine Society clinical practice guideline. Journal of Clinical Endocrinology and Metabolism 200893 1526-1540. (https://doi. org/10.1210/jc.2008-0125)

270 Lopes LM, Francisco RP, Galletta MA \& Bronstein MD. Determination of nighttime salivary cortisol during pregnancy: comparison with values in non-pregnancy and Cushing's disease. Pituitary 201619 30-38. (https://doi.org/10.1007/s11102-015-0680-3)

271 Brue T, Amodru V \& Castinetti F. Management of endocrine disease: management of Cushing's syndrome during pregnancy: solved and unsolved questions. European Journal of Endocrinology 2018178 R259-R266. (https://doi.org/10.1530/EJE-17-1058)

272 Machado MC, Fragoso MCBV \& Bronstein MD. Pregnancy in patients with Cushing's syndrome. Endocrinology and Metabolism Clinics of North America 201847 441-449. (https://doi.org/10.1016/j.ecl.2018.02.004)

273 Martínez García R, Martínez Pérez A, Domingo del Pozo C \& Sospedra Ferrer R. Cushing's syndrome in pregnancy. Laparoscopic adrenalectomy during pregnancy: the mainstay treatment. Journal of Endocrinological Investigation 201639 273-276. (https://doi. org/10.1007/s40618-015-0345-0)

274 Stuijver DJ, van Zaane B, Feelders RA, Debeij J, Cannegieter SC, Hermus AR, van den Berg G, Pereira AM, de Herder WW, Wagenmakers MA et al. Incidence of venous thromboembolism in patients with Cushing's syndrome: a multicenter cohort study. Journal of Clinical Endocrinology and Metabolism 201196 3525-3532. (https:// doi.org/10.1210/jc.2011-1661)

275 Suarez MG, Stack M, Hinojosa-Amaya JM, Mitchell MD, Varlamov EV, Yedinak CG, Cetas JS, Sheppard B \& Fleseriu M. Hypercoagulability in Cushing syndrome, prevalence of thrombotic events: a large, single-center, retrospective study. Journal of the Endocrine Society 20204 bvz033. (https://doi.org/10.1210/jendso/bvz033)

276 Pivonello R, Isidori AM, de Martino MC, Newell-Price J, Biller BM \& Colao A. Complications of Cushing's syndrome: state of the art. Lancet: Diabetes and Endocrinology 20164 611-629. (https://doi. org/10.1016/S2213-8587(16)00086-3)

277 Boscaro M, Sonino N, Scarda A, Barzon L, Fallo F, Sartori MT, Patrassi GM \& Girolami A. Anticoagulant prophylaxis markedly reduces thromboembolic complications in Cushing's syndrome. Journal of Clinical Endocrinology and Metabolism 200287 3662-3666. (https://doi.org/10.1210/jcem.87.8.8703)

278 Jung C, Ho JT, Torpy DJ, Rogers A, Doogue M, Lewis JG, Czajko RJ \& Inder WJ. A longitudinal study of plasma and urinary cortisol in pregnancy and postpartum. Journal of Clinical Endocrinology and Metabolism 201196 1533-1540. (https://doi.org/10.1210/jc.2010-2395) 